ARTICLE

\title{
Delta-secretase cleaves amyloid precursor protein and regulates the pathogenesis in Alzheimer's disease
}

\author{
Zhentao Zhang1,2, Mingke Song ${ }^{3}$, Xia Liu1, Seong Su Kang ${ }^{1}$, Duc M. Duong ${ }^{4,5}$, Nicholas T. Seyfried ${ }^{4,5}$, \\ Xuebing $\mathrm{Cao}^{6}$, Liming Cheng ${ }^{7}$, Yi E. Sun ${ }^{7,8}$, Shan Ping Yu ${ }^{3}$, Jianping Jia ${ }^{9}$, Allan I. Levey ${ }^{4}$ \& Keqiang $\mathrm{Ye}^{1}$
}

The age-dependent deposition of amyloid- $\beta$ peptides, derived from amyloid precursor protein (APP), is a neuropathological hallmark of Alzheimer's disease (AD). Despite age being the greatest risk factor for $A D$, the molecular mechanisms linking ageing to APP processing are unknown. Here we show that asparagine endopeptidase (AEP), a pH-controlled cysteine proteinase, is activated during ageing and mediates APP proteolytic processing. AEP cleaves APP at N373 and N585 residues, selectively influencing the amyloidogenic fragmentation of APP. AEP is activated in normal mice in an age-dependent manner, and is strongly activated in 5XFAD transgenic mouse model and human AD brains. Deletion of AEP from 5XFAD or APP/PS1 mice decreases senile plaque formation, ameliorates synapse loss, elevates long-term potentiation and protects memory. Blockade of APP cleavage by AEP in mice alleviates pathological and behavioural deficits. Thus, AEP acts as a $\delta$-secretase, contributing to the age-dependent pathogenic mechanisms in AD.

\footnotetext{
${ }^{1}$ Department of Pathology and Laboratory Medicine, Emory University School of Medicine, Atlanta, Georgia 30322, USA. ${ }^{2}$ Department of Neurology, Renmin Hospital of Wuhan University, Wuhan 430060, China. ${ }^{3}$ Department of Anesthesiology, Emory University School of Medicine, Atlanta, Georgia 30322, USA. ${ }^{4}$ Department of Neurology, Center for Neurodegenerative Diseases, Emory University School of Medicine, Atlanta, Georgia 30322, USA. ${ }^{5}$ Department of Biochemistry, Center for Neurodegenerative Diseases, Emory University School of Medicine, Atlanta, Georgia 30322, USA. ${ }^{6}$ Department of Neurology, Union Hospital, Tongji Medical College, Huazhong University of Science and Technology, Wuhan 430022, China. ${ }^{7}$ Translational Center for Stem Cell Research, Tongji Hospital, Department of Regenerative Medicine, Tongji University School of Medicine, Shanghai 200065, China. ${ }^{8}$ Department of Psychiatry and Biobehavioral Sciences, UCLA School of Medicine, Los Angeles, California 90095, USA. ${ }^{9}$ Department of Neurology, Xuan Wu Hospital of Capital Medical University, 45 Changchun Street, Beijing 100053, China. Correspondence and requests for materials should be addressed to Y.S.

(email: yi.eve.sun@gmail.com) or to J.J. (email: jiajp@vip.126.com) or to K.Y. (email: kye@emory.edu).
} 
myloid $\beta(\mathrm{A} \beta)$ is a key pathogenic factor in Alzheimer's disease $(\mathrm{AD})$. It aggregates to form neurotoxic oligomers and insoluble deposits in plaques in the brains of affected individuals, contributing to the progressive loss of synaptic function and cognitive impairment. $A \beta$ peptides are derived from the sequential proteolytic processing of amyloid precursor protein (APP) by a group of proteases ${ }^{1,2}$. APP is a type I oriented membrane protein with its amino terminus within the lumen/extracellular space and its carboxyl terminus within the cytosol $^{3,4}$. Three proteases, $\alpha$-, $\beta$ - and $\gamma$-secretases, regulate APP processing ${ }^{2}$. Commitment of APP into amyloidogenic and non-amyloidogenic processing depends on the cellular levels of $\alpha$ - and $\beta$-secretases and the traffic of APP to subcellular organelles expressing these proteases. The amyloidogenic pathway leads to $A \beta$ generation, while the anti-amyloidogenic pathway prevents $A \beta$ generation ${ }^{5}$.

$\beta$-Secretase activity mediates the initial and rate-limiting processing step leading to $A \beta$ generation $^{6}$. $\beta$-Secretase (BACE1) is a membrane-bound aspartyl protease with its active site in the lumen/extracellular space ${ }^{7}$ and an acidic $\mathrm{pH}$ optimum (around $\mathrm{pH} 4.5$; ref. 8), consistent with the major site of $\beta$-secretase activity within endosomes. The $\beta$-secretase-cleaved $\mathrm{C}$-terminal portion of APP is subsequently processed by $\gamma$-secretase to liberate A $\beta$. Mounting evidence shows that $\gamma$-secretase cleaves APP in the endosomal/lysosomal system, including phagosomes and autophagosomes ${ }^{9}$. The protease activity of $\gamma$-secretase is also regulated by $\mathrm{pH}$ with optimal activity at $\mathrm{pH} 6.3$ (ref. 10). An alternative pathway of anti-amyloidogenic processing of APP occurs within the A $\beta$ domain between residues K612 and L613 in $\mathrm{APP}^{11,12}$ and results in the secretion of the large APP aminoterminal domain and the generation of $\alpha$-CTF (C83). This cleavage is performed by $\alpha$-secretases, which in neurons includes ADAM10 (ref. 13). $\alpha$-Secretase processing of APP occurs in the trans-Golgi network and the plasma membrane ${ }^{14}$. On the basis of the relative BACE1 expression levels, neurons have been suggested to be the major source of $A \beta$ produced in the brain ${ }^{5}$.

Mammalian asparagine endopeptidase (AEP), also known as legumain, is a widely distributed lysosomal cysteine protease that cleaves after asparagine residues ${ }^{15,16}$. AEP activation is autocatalytic and requires sequential removal of $\mathrm{C}$ - and $\mathrm{N}$-terminal propeptides at different $\mathrm{pH}$ thresholds ${ }^{17}$. Disruption of AEP leads to late endosome and lysosome abnormalities with accumulation of electron-dense and/or membranous materials ${ }^{18}$. AEP has diverse physiological functions in the brain. Neuronal AEP is activated by acidosis during excitotoxicity and contributes to neuronal apoptosis by degrading the DNase inhibitor SET, a binding partner of $\mathrm{APP}{ }^{19,20}$. AEP cleavage of SET $\left(\mathrm{I}_{2}^{\mathrm{PP} 2 \mathrm{~A}}\right.$ ) inhibits PP2A and upregulates tau hyperphosphorylation ${ }^{21}$. AEP also cleaves TDP-43 in human cases of frontotemporal lobar degeneration ${ }^{22}$. Moreover, AEP cleaves tau, mediating neurofibrillary pathology in $\mathrm{AD}^{23}$. AEP is inhibited by cystatin $\mathrm{C}$, a secreted protein found in human cerebrospinal fluid (CSF) that binds soluble $A \beta$ and inhibits its oligomerization, and which is reduced in $\mathrm{AD}^{24,25}$. Cystatin $\mathrm{C}$ interacts with active AEP in the lysosome and acts as an endogenous inhibitor of $\mathrm{AEP}^{26,27}$. Together, these observations led us to hypothesize that AEP plays an important role in $\mathrm{AD}$ pathogenesis.

In this report, we show that APP is a physiological substrate of AEP. AEP increases with ageing and proteolytically cleaves APP in the ectodomain, affecting the rate of BACE1 cleavage of the resultant substrate. Knockout of AEP in vivo using 5XFAD and $\mathrm{APP} / \mathrm{PS} 1$ mouse models of $\mathrm{AD}$ reduces $\mathrm{A} \beta$ burden, improves synapse integrity and preserves memory. Blockade of APP cleavage by AEP prevents pathological and behavioural defects induced by overexpression of APP. These findings suggest that $\mathrm{AEP}$ is activated during ageing and promotes $\mathrm{A} \beta$ production, contributing to $\mathrm{AD}$ onset and progression. Hence, AEP may act as a novel $\delta$-secretase that mediates APP fragmentation and amyloidogenesis.

\section{Results}

APP is a physiological substrate of AEP. To investigate whether APP is a substrate of AEP, we prepared kidney lysates derived from wild-type (WT; $+/+$ ) or AEP knockout $(-/-)$ mice at different $\mathrm{pH}$ to inactivate ( $\mathrm{pH}$ 7.4) or activate AEP ( $\mathrm{pH}$ 6.0), respectively, and incubated with recombinant green fluorescent protein (GFP)-APP. Immunoblotting analysis revealed robust APP cleavage with two major fragments in WT samples under $\mathrm{pH} 6.0$ but not pH 7.4. By contrast, we failed to observe any APP cleavage in AEP-null samples regardless of $\mathrm{pH}$ values. We also validated the APP fragmentation with anti-APP $\mathrm{N}$-terminal antibody (Fig. 1a, left panels), and confirmed the $\mathrm{pH}$ dependence of AEP enzyme activity in WT samples (Fig. 1a, right panel). We used inhibitory anti-AEP antibodies to verify the role of AEP. As anti-AEP doses gradually increased, APP fragmentation was progressively inhibited and completely blocked at $50 \mu \mathrm{g} \mathrm{ml}^{-1}$. In contrast, the same concentrations of anti-mouse IgG failed to block APP cleavage (Fig. 1b). Mutation of either of two key residues in AEP blunted its proteolytic activity against APP (Fig. 1c), including C189 that is essential for the cysteine proteinase activity and N323 that plays a critical role in the cleavage and maturation of $\mathrm{AEP}^{17,19}$. In addition, the selective AEP inhibitor peptide AENK suppressed APP cleavage, while an inactive peptide AEQK had no effect ${ }^{28}$. AEP enzymatic activity tightly correlated with the APP shedding pattern (Fig. 1d). We also explored whether or not endogenous APP in mouse brain can be processed by AEP. Endogenous APP was robustly cleaved in WT $\left(\mathrm{AEP}^{+/+}\right)$mouse brain lysates with acidic conditions that activate AEP, whereas the cleavage was abrogated at $\mathrm{pH} 7.4$ where AEP is catalytically inactive. APP cleavage was also absent in brain lysates from AEP knockout mice (AEP ${ }^{-/-}$; Fig. 1e). To ascertain if APP is indeed a direct substrate of AEP, we incubated purified glutathione S-transferases (GST)-APP with active recombinant human AEP. AEP potently cleaved GST-APP recombinant proteins with the same pattern as in the tissues (Fig. 1f). Thus, the biochemical cleavage assay, antibody or peptide inhibition assay and studies with AEP knockout tissues all indicate that APP is a physiological substrate of AEP.

AEP cleaves APP at N373 and N585 residues. To identify potential AEP cleavage sites on APP, we generated a series of truncated APP proteins with sequential deletions of N-terminal domains (Supplementary Fig. 1) and tested them in the biochemical cleavage assay. Deletion of the $\mathrm{N}$ terminus proximal to amino acid 289 did not affect APP cleavage (Supplementary Fig. 1), indicating that AEP cleaves APP after residue 289. Next, we purified the cleaved recombinant protein products and analysed them by mass spectrometry (MS), identifying two main cleavage sites at N585 and N373 that yield fragments of molecular weight $\sim 130$ and $80 \mathrm{kDa}$, respectively (Fig. 2a). The amino acid number is based on the APP695 isoform. To determine if the same APP cleavages occur in human brain from AD cases, we immunoprecipitated brain lysates with anti-APP N-terminal antibody and subjected the samples to proteomic analysis. An APP fragment terminated at N585 was detected (Fig. 2b). Mutations of N373A or N585A abolished the $80-$ or $130-\mathrm{kDa}$ fragments, respectively, and the APP double mutant (N373A/ N585A) was resistant to both cleavages. By contrast, mutations at other sites (N391A, N400A or N417A) had no effect on APP fragmentation (Fig. 2c). Thus, these studies suggest that N373 and N585 are the two major AEP cleavage sites in APP. 


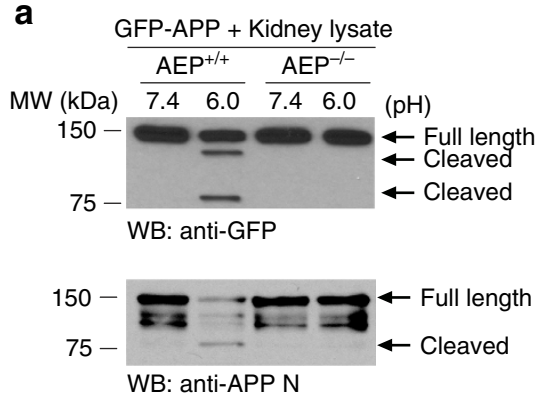

b

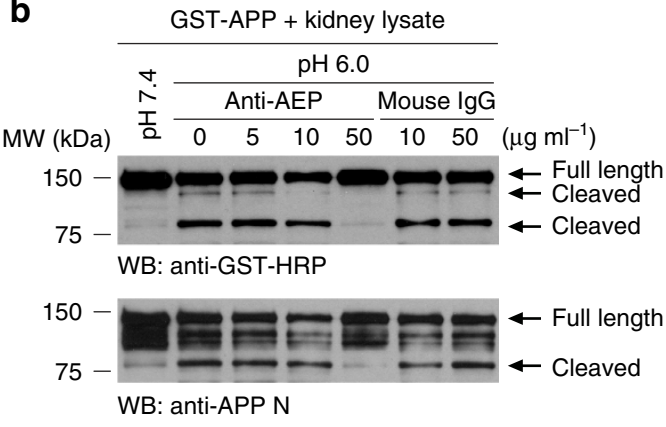

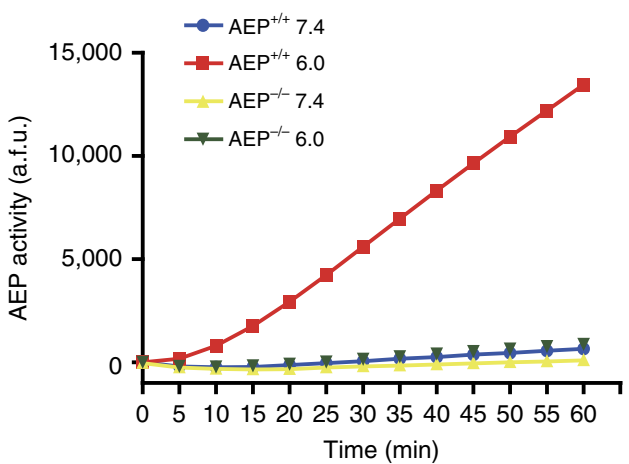

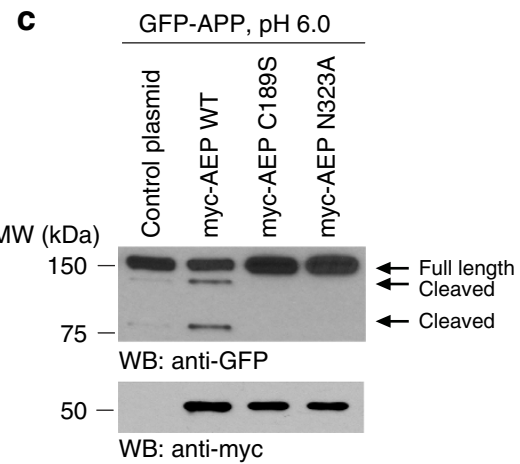

d

GFP-APP + kidney lysate

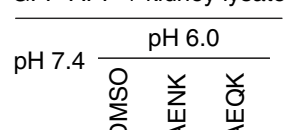
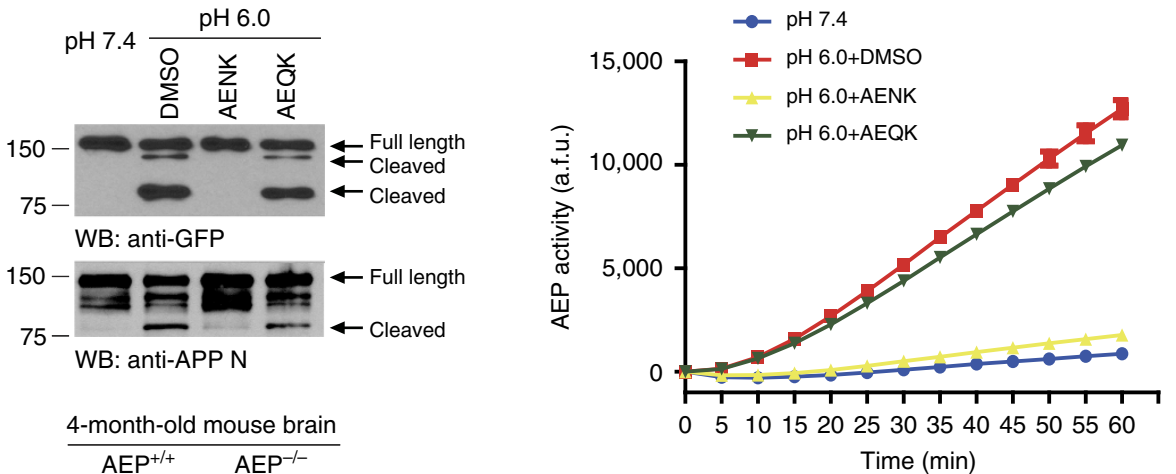

e 4-month-old mouse brain

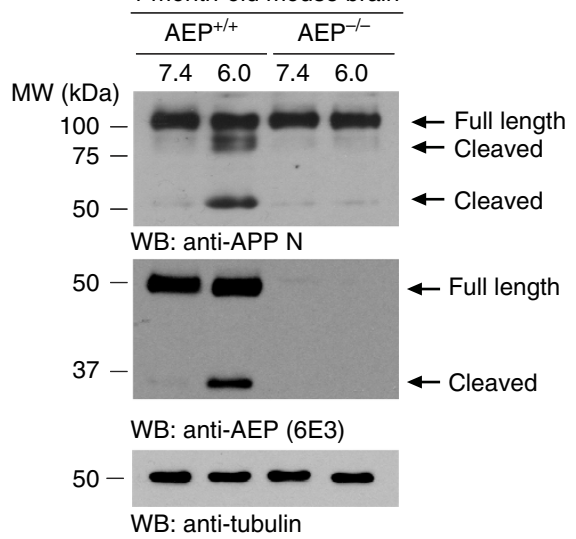

$\mathbf{f}$

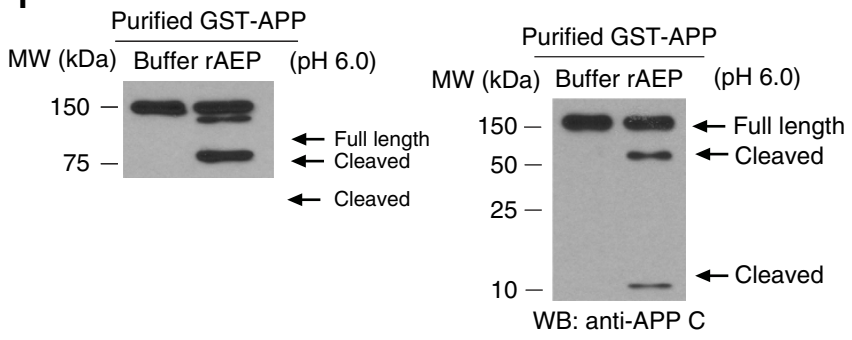

Figure 1 | AEP cleaves APP in vitro. (a) APP cleavage by AEP $+/+$ kidney lysates. APP was cleaved at pH 6.0 by AEP $+/+$ kidney lysates (left panels). The enzymatic activity of AEP was determined using AEP activity assay (right panel; mean \pm s.e.m. of three independent experiments). (b) Antibody titration assay. Kidney lysates were incubated with AEP-specific antibody for $5 \mathrm{~min}$, and then incubated with GST-APP for 30 min. The processing of APP was determined using western blot. (c) Mutants of AEP C189 and N323 diminish APP cleavage. (d) Blocked of APP cleavage by Fmoc-Ala-Glu-Asn-Lys-NH2 (AENK) peptide (left panel). AEP activity was inhibited by AENK but not by Fmoc-Ala-Glu-Gln-Lys-NH2 (AEQK) (right panel; mean \pm s.e.m.; $n=3$ ). (e) Cleavage of endogenous APP by AEP. (f) Western blot showing the processing of purified GST-APP by recombinant AEP. The AEP-derived APP fragments were detected using anti-APP N-terminal antibody (left panel) and anti-APP C-terminal antibody (right panel). a.f.u., arbitrary fluorescence unit; DMSO, dimethylsulfoxide; MW, molecular weight; WB, western blot. 
a
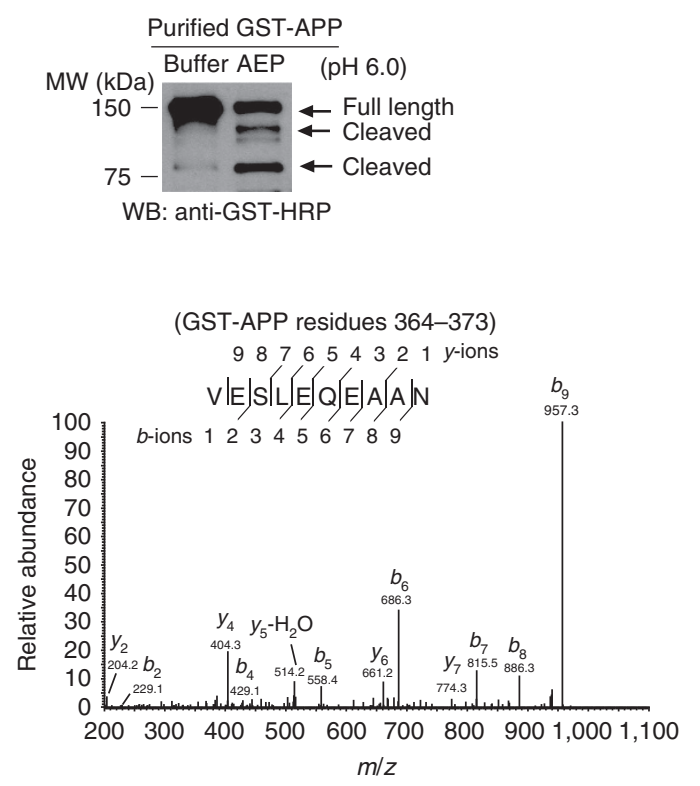

C

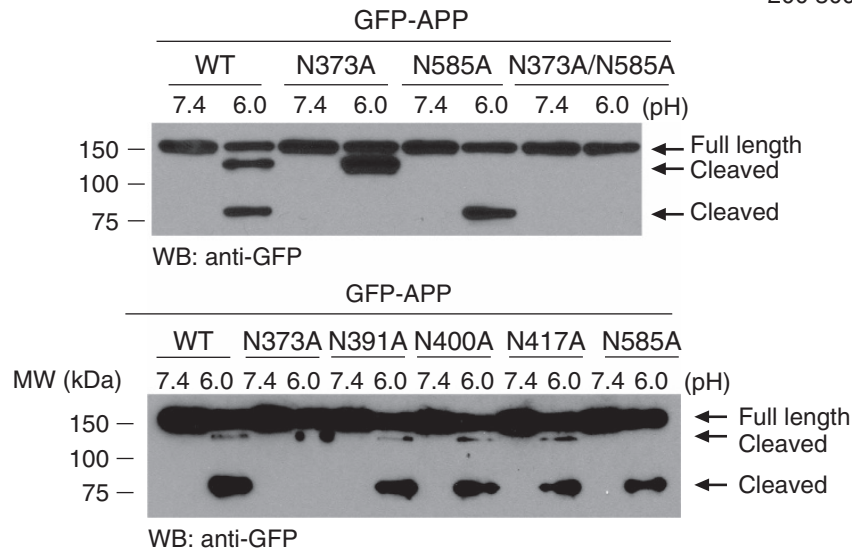

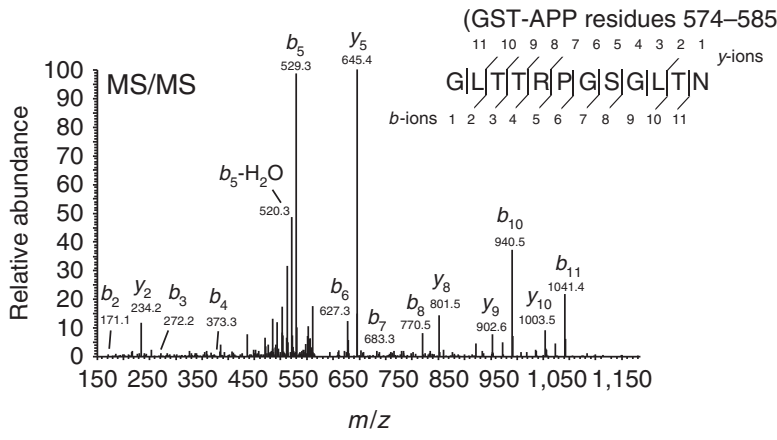

b

(AD brain-APP residues 574-585)

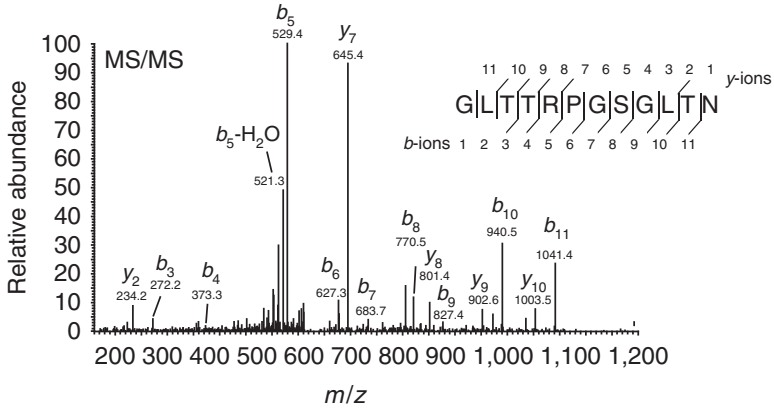

Figure 2 | AEP cleaves APP at N373 and N585 residues. (a) Proteomic analysis of APP recombinant proteins processed by AEP. The detected peptide sequences indicate that N585 and N373 are the two main cleavage sites with the shed bands of molecular weight (MW) 130 and $80 \mathrm{kDa}$, respectively. (b) Proteomic analysis of APP fragments in AD brain. APP fragments cleaved after N585 was detected. (c) Processing of various mutant APP by AEP.

AEP regulates A $\beta$ production. APP can be processed by several proteases, with both $\alpha$ - and $\beta$-secretases shedding APP ectodomains (Fig. 3a). To determine if AEP processing of APP affects $\alpha$ - and $\beta$-secretase cleavages, recombinant APP proteins corresponding to the two AEP-processed derivatives ( $\mathrm{APP}_{374-695}$ and $\mathrm{APP}_{586-695}$ ) were tested as substrates for ADAM10 and BACE1 protease, respectively. BACE1 processed both full-length APP and the truncated $\mathrm{APP}_{374-695}$ fragment at the same rate. Interestingly, BACE1 processing of the APP $\mathrm{AP6}_{595}$ fragment yielded more C99 product than full-length APP or $\mathrm{APP}_{374-695}$ (Fig. 3b). By contrast, ADAM10 processed all these proteins at the same rate (Fig. $3 \mathrm{c}$ ), indicating that $\mathrm{APP}_{586-695}$ might be a better substrate for BACE1 than full-length APP or APP $374-695$. To further test this possibility, we incubated purified GST-APP ${ }_{586-695}$ with BACE1 in the presence or absence of AEP-generated APP N-terminal fragment $\mathrm{APP}_{1-373}$ or $\mathrm{APP}_{1-585}$, respectively. $\mathrm{APP}_{1-585}$, but not $\mathrm{APP}_{1-373}$ decreased C99 production in a concentration-dependent manner (Supplementary Fig. 2a). However, AEP-generated APP $\mathrm{N}$-terminal fragments had no effect on ADAM10 cleavage of $\mathrm{APP}_{586-695}$ (Supplementary Fig. 2b). These data suggest that the
$\mathrm{N}$ terminus of $\mathrm{APP}_{1-585}$ might inhibit $\mathrm{BACE} 1$ processing of the resultant cleavage product $\mathrm{APP}_{586-695}$. Conceivably, cleavage of APP by AEP at N585 may relieve the steric hindrance of the N terminus and thereby accelerate APP processing by BACE1. Since $\mathrm{BACE} 1$ is the rate-limiting enzyme for $\mathrm{A} \beta$ production, we also explored the role of AEP in $A \beta$ production in neurons. Remarkably, while total APP protein levels were similar between WT and AEP $-1-$ neurons, the concentrations of $\mathrm{A} \beta 40$ and $\mathrm{A} \beta 42$ in the conditioned medium of $\mathrm{AEP}^{-1}$ - cultures were significantly lower than those in $\mathrm{AEP}^{+/+}$cultures. The concentration of $\operatorname{sAPP} \alpha$ in the $\mathrm{AEP}^{-/-}$conditioned medium was higher than that of $\mathrm{AEP}^{+I+}$ cultures (Fig. 3d). Though AEP is assumed to be highly expressed in microglia ${ }^{29}$, we found it is abundant in primary neuronal cultures as well. The percentage of neurons was about $96 \%$ in both $\mathrm{AEP}^{+l+}$ and $\mathrm{AEP}^{-1-}$ neuronal cultures (Supplementary Fig. 2c). To further confirm these results, we transfected HEK293 cells stably expressing human APP with two different AEP siRNAs or control siRNA. Depletion of AEP in these cells significantly reduced $A \beta$ production and increased $\operatorname{sAPP} \alpha$ levels without altering the level of total APP (Fig. 3e). 
a $\beta$-secretase (596)

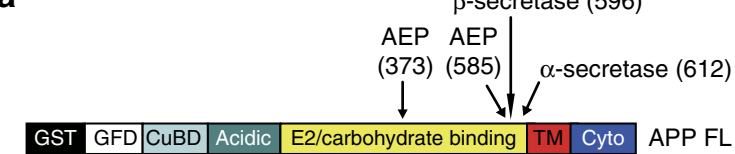

$\operatorname{AEP}(585) \beta$-secretase (596)

$\alpha$-secretase (612)

GST GFD

-SGLTNIKTEEISEVKMDAEFRHDSGYEVHHQKLVF-

\begin{tabular}{l|l|l|l|l|l}
\hline GST & E2 & TM & Cyto & APP (374-695)
\end{tabular}

GST E2 TM

b

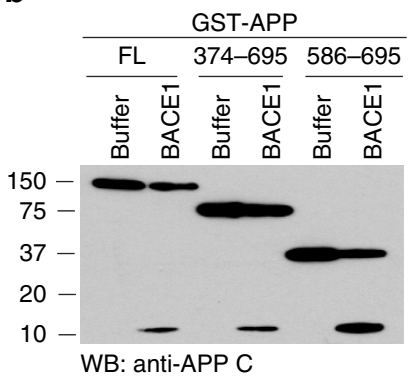

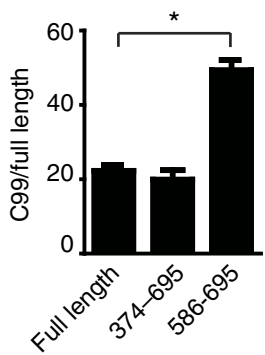

C
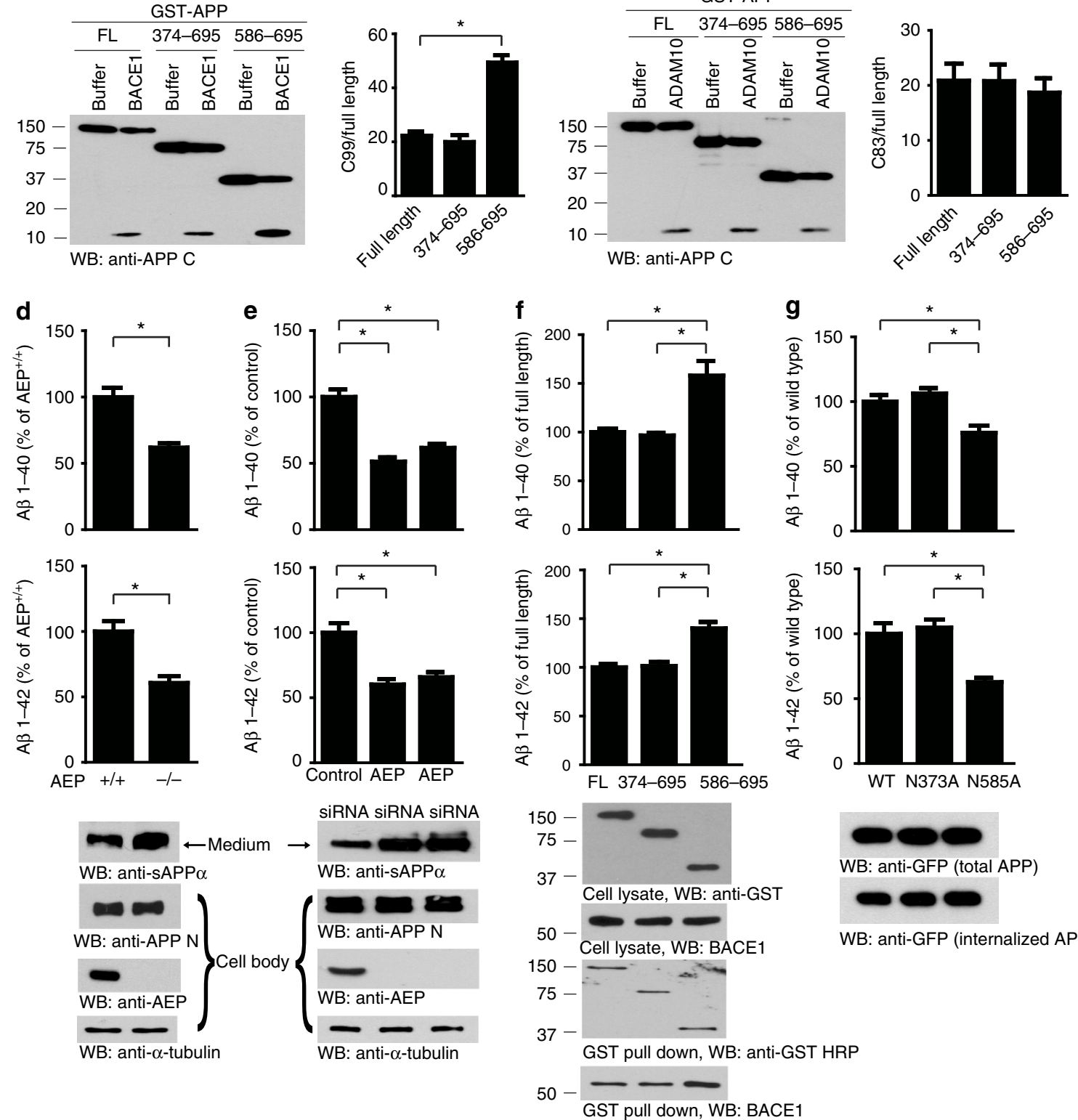

Figure 3 | Cleavage of APP by AEP at N585 accelerates A $\beta$ production. (a) Schematic drawing of APP cleavage by AEP, $\beta$-secretase and $\alpha$-secretase. $(\mathbf{b}, \mathbf{c})$ Western blot $(\mathrm{WB})$ showing the processing of APP fragments by $\alpha$ - and $\beta$-secretase. Arrows indicate APP C-terminal fragments generated by $\operatorname{BACE} 1(C 99, \mathbf{b})$ and ADAM10 $(C 83, \mathbf{c})$. The percentage of $C 99$ and $C 83$ was quantified. (d-g) ELISA results showing the concentrations of A $\beta 1-40$ and A $\beta$ 1-42 in medium from AEP $+/+$ and AEP ${ }^{-/-}$primary neurons (d), HEK293 cells stably transfected with APP (e), HEK293 cells transiently transfected with GST-tagged APP fragments (f) or GFP-tagged mutant APP ( $(\mathbf{g})$. The binding of APP fragments with BACE1 was analysed using GST pull-down assay (f). The internalized APP was assessed by internalization assay $(\mathbf{g})$. Data are mean \pm s.e.m. of three independent experiments, and were analysed using one-way analysis of variance followed by post hoc comparison, ${ }^{\star} P<0.01$.

Conversely, overexpression of the $\mathrm{APP}_{586-695}$ fragment markedly elevated $A \beta$ production compared with overexpression of fulllength APP and the $\mathrm{APP}_{374-695}$ fragment. To further evaluate the substrate preference of BACE1 for the various forms of APP, we also carried out GST pull-down assays, and found that the $\mathrm{APP}_{586-695}$ fragment bound more BACE1 than full-length APP and $\mathrm{APP}_{374-695}$ (Fig. 3f). Furthermore, when the $\mathrm{APP}_{596-695}$ fragment was co-expressed in HEK293 cells with increasing 
amounts of the myc-APP ${ }_{1-585}$ or myc- $\mathrm{APP}_{1-373}$, the longer $\mathrm{APP}_{1-585}$ fragment selectively decreased the production of $\mathrm{A} \beta$ in a dose-dependent manner and reduced the binding of BACE1 to $\mathrm{APP}_{586-695}$ (Supplementary Fig. 2d). Accordingly, APP mutation analysis revealed $A \beta$ production was reduced by inhibition of AEP cleavage of APP at N585, but not at N373. Since cell surface trafficking of APP affects its processing, we tested the possibility that these mutations affect the internalization of cell surface APP. Cell surface biotinylation assays demonstrated that neither the N585 nor the N373 mutations had any effect on APP internalization (Fig. 3g). Hence, AEP cleavage of APP at N585 facilitates the subsequent processing by BACE1 and generation of $\mathrm{A} \beta$.

Since AEP pre-processing of APP directly influences subsequent cleavage by BACE1, we sought to determine if other proteases might affect AEP cleavage of APP. APP is processed by caspase- 3 and cathepsin in addition to the secretases ${ }^{30,31}$. We employed pharmacological inhibitors of these proteases and found that only the AEP inhibitory peptide AENK antagonized APP processing by AEP, whereas other small molecular inhibitors and inactive peptide $A E Q K$ were without effect (Supplementary Fig. 3a). Moreover, APP point mutants that influence cleavage by a variety of secretases were strongly cleaved by AEP (Supplementary Fig. 3b), suggesting that APP cleavage by secretases does not affect AEP processing of its substrate APP. To further define the role of BACE1, $\gamma$-secretase or $\alpha$-secretase in AEP processing of APP, we also used BACE1 ${ }^{-1-}, \mathrm{PS} 1 / \mathrm{PS} 2^{-1-}$ and ADAM10/17 ${ }^{-/-}$mouse embryonic fibroblast cells. Proteolytic analysis revealed that AEP initiated APP fragmentation in a time-dependent manner with comparable rates regardless of the presence or absence of BACE1, $\gamma$-secretase or $\alpha$-secretase (Supplementary Fig. 3c). Therefore, these studies demonstrate that the secretases do not interfere with AEP's cleavage of APP.

AEP interacts with APP in the endolysosomal organelles. To explore how a lysosomal protease AEP cleaves APP and leads to secretion of the relevant APP fragments, we investigated the subcellular basis for the interaction between AEP and APP in brain. Brain samples from WT, 5XFAD and tau P301S mice were fractionated by differential centrifugation on a sucrose discontinuous gradient to separate cellular organelles. For the WT brain samples, AEP was enriched in fractions 9 and 10, containing the specific lysosomal marker LAMP1, and APP was enriched in fractions 4-6, co-enriched with EEA1, a specific marker for the endosome, and GGA3, a Golgi-localized adaptor protein involved in BACE1 trafficking ${ }^{32}$ (Fig. 4a). In the aged WT mouse brain, 5XFAD and tau P301S transgenic mouse brain, AEP distribution was more widely distributed in fractions 5-12, consistent with its upregulation during ageing and in $\mathrm{AD}$ (Fig. 6). Moreover, AEP overlapped with APP in fractions 5 and 6 together with the endolysosomal markers LAMP1 and EEA1. BACE1 was highly enriched in the same fractions (Fig. $4 \mathrm{~b}$ and Supplementary Fig. 4a,b). To detect the APP fragments derived from AEP processing in the fractionated brain samples, we developed cleavage-site-specific antibodies, which selectively bind the following AEP-derived fragments: $\mathrm{APP}_{1-373}$ (anti-APP 373N), $\mathrm{APP}_{1-585}$ (anti-APP 585N) and $\mathrm{APP}_{586-695}$ (anti-APP 585C). The specificity of these antibodies was confirmed by western blot and immunohistochemistry (Supplementary Fig. 5a-e). $\mathrm{APP}_{1-373}$ and $\mathrm{APP}_{1-585}$ fragments were enriched in fractions 5 and 6 of 5XFAD mice. Thus, these data suggest that AEP cleaves APP in the endolysosomal system. Accordingly, the cleavage of APP by AEP in endolysosomes may promote the subsequent BACE1 cleavage and production of $A \beta$.

$\mathrm{A} \beta$ exerts a variety of deleterious effects on cells including altering membrane protein traffic ${ }^{33}$. To explore the effects of $A \beta$ on the membranous compartments where AEP may cleave APP, we treated primary cortical neurons with different doses of pre-aggregated $A \beta$ for $24 \mathrm{~h}$ and determined the subcellular distribution of APP and AEP by immunofluorescent staining. Remarkably, $A \beta(20 \mu \mathrm{M})$ treatment triggered the co-localization of APP and AEP in primary neurons (Fig. 4c, left panels and Supplementary Fig. 6a). APP also co-localized with the endosomal marker EEA1 (Fig. 4c, right panels and Supplementary Fig. 6b). The co-localization of AEP with EEA1 and LAMP1 in A $\beta$-treated neurons and 5XFAD mice brain was confirmed by confocal microscopy (Supplementary Fig. 6c-f). Notably, A $\beta$ treatment elicited AEP expression and activation (Fig. 4d). Using an internalization assay, we found that $A \beta$ treatment promoted the endocytosis of APP (Fig. 4e). Moreover, APP and AEP were co-immunoprecipitated from both WT and 5XFAD brain lysates, confirming their interaction (Fig. 4f).

AEP is secreted extracellularly in the tumour microenvironment and associated with cell surface ${ }^{26}$. We found that AEP was secreted into the CSF, and interestingly, the AEP-cleaved $\mathrm{APP}_{1-585}$ fragment was significantly higher in human AD CSF than in healthy controls (Supplementary Fig. 7a,b). Furthermore, exogenous His-tagged AEP recombinant proteins bound to APP on the cell surface, and were internalized and subsequently processed to the active form (Supplementary Fig. 7c,d). Thus, AEP interacts with APP on the cell surface, and the complex may be endocytosed. To study how $A \beta$ peptides are secreted from the endolysosome system, we treated HEK293 cells stably transfected with human APP, with tetanus toxin, a well-established inhibitor of exocytosis. Inhibition of exocytosis increased the $A \beta$ levels in the cell body (Supplementary Fig. 7e), indicating that $A \beta$ may be exocytosed, fitting with previous observations $s^{3}$. Hence, our data support that AEP interacts with APP and proteolytically processes it in the endolysosomal organelles.

APP N-terminal ectodomain shed by AEP cleavage is neurotoxic. Accumulating evidence indicates that the ectodomain of APP cleavage may be tied to neurodegeneration in $\mathrm{AD}^{35,36}$. Next, we assessed whether the AEP-derived APP fragments influence neuronal viability. Strikingly, treatment of primary neurons with purified recombinant His-tagged $\mathrm{APP}_{1-373}$, mimicking the AEP-derived secreted APP fragment, triggered extensive axonal fragmentation and neuronal cell death. In contrast, sAPP $\alpha$, sAPP $\beta, \mathrm{APP}_{1-585}$ and $\mathrm{APP}_{374-585}$ fragments did not exhibit any demonstrable neurotoxic effect (Fig. 5a-c). TUNEL staining showed that the N-terminal APP ${ }_{1-373}$ fragment $\left(10 \mu \mathrm{g} \mathrm{ml}^{-1}\right)$ induced apoptosis (Fig. 5d,e). The $\mathrm{APP}_{1-373}$ fragment was not toxic to either PC12 cells or HEK293 cells (Fig. 5f,g), suggesting the toxic effect is specific to certain cell types, especially neurons. However, the AEP-derived APP fragments did not induce neuronal apoptosis when expressed within neurons (Fig. 5h), suggesting that only secreted $\mathrm{N}$-terminal $\mathrm{APP}_{1-373}$ fragment is neurotoxic, presumably by binding to cell surface receptors. As shown earlier, the AEP cleavage of APP at N585 accelerates $\mathrm{BACE} 1$ processing of the resultant $\mathrm{APP}_{586-695}$ fragment. Hence, the combined effects of the two AEP cleavages of APP, leading to increased levels of the neurotoxic secreted $\mathrm{APP}_{1-373}$ and $\mathrm{A} \beta$ products, respectively, would be deleterious in $\mathrm{AD}$.

AEP is upregulated and activated during ageing and in AD. The greatest known risk factor for $\mathrm{AD}$ is increasing age. We assessed AEP activity in ageing brain. AEP protein levels were barely detectable in the brain at 2 or 3 months of age, but escalated at 4 months and continued to increase substantially with age. AEP enzymatic activity is dependent on an 
a

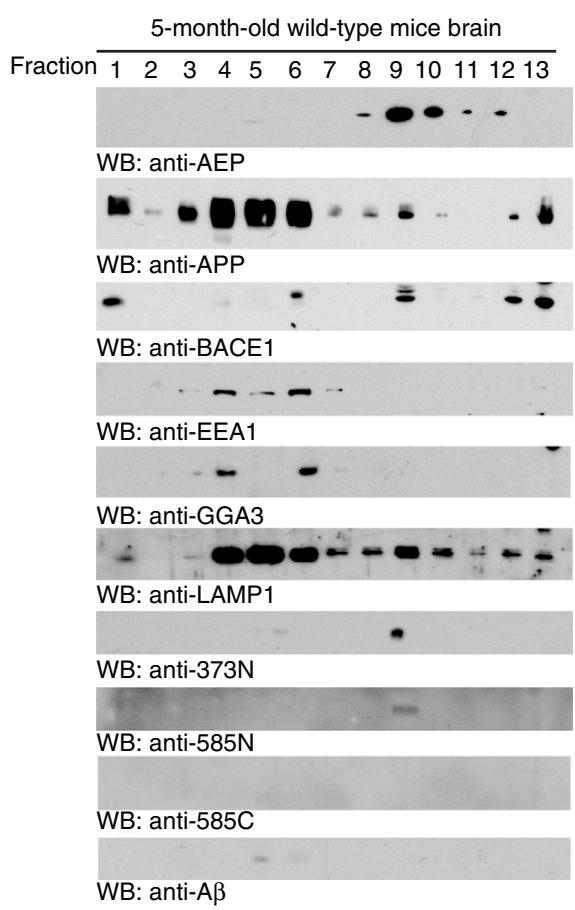

b

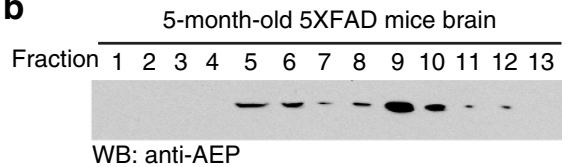

WB: anti-AEP

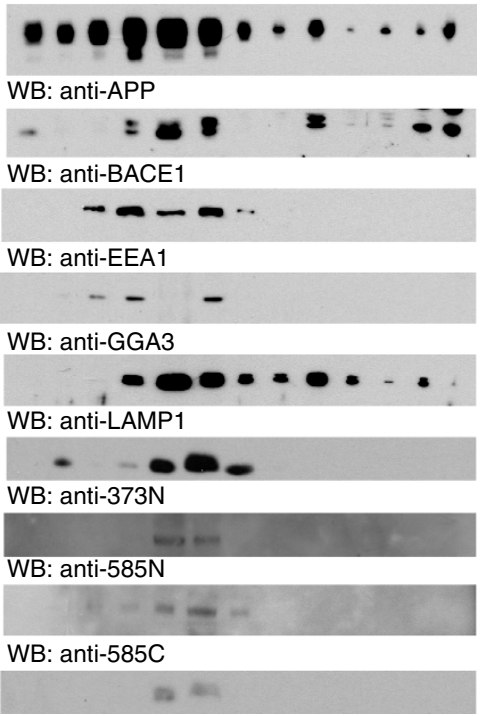

WB: anti-A $\beta$

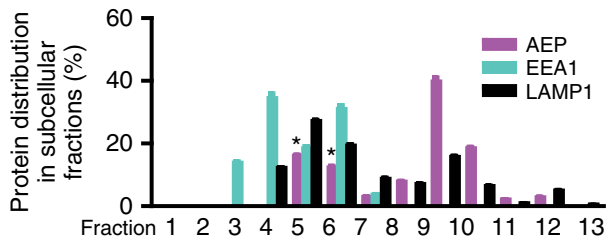

C

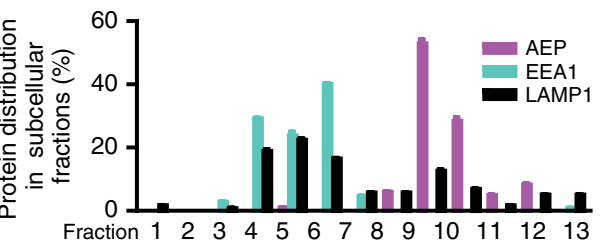

EEA1
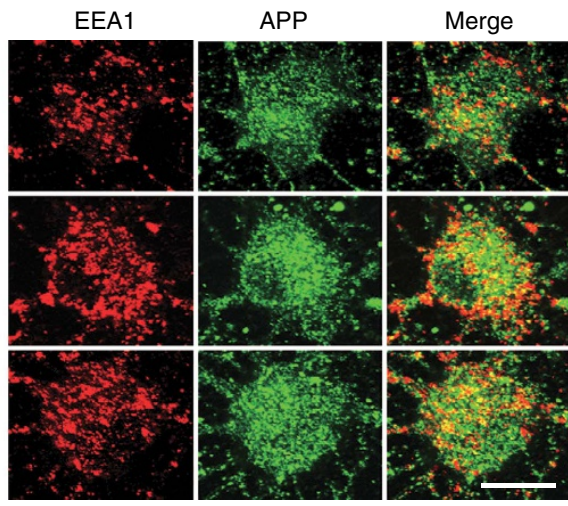

d

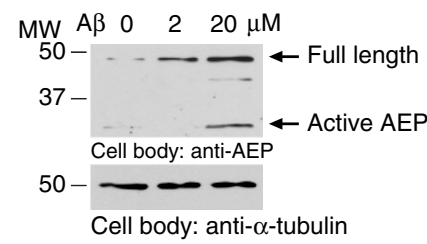

e

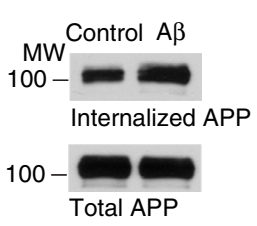

f Wild type 5XFAD

IP: anti-AEP $\lg G \overline{\text { anti-AEP } \lg G}$ MW

WB: anti-APP N Brain lysate

$100-$

WB: anti-APP N

Figure 4 | AEP interacts with APP in the endolysosomal system. (a,b) AEP and APP distribution in the subcellular fractions. Brain samples from 5-month-old WT (a) and age-matched $\operatorname{XXFA}(\mathbf{b})$ mice were homogenated and fractionated on a discontinuous sucrose gradient. The fractions were analysed by western blotting (WB) for AEP, APP fragments, BACE1, EEA1 (endosome marker), GGA3 (trans-Golgi network maker) and LAMP1 (lysosome marker). The relative amount of AEP, EEA1 and LAMP1 in each fraction was quantified (mean \pm s.e.m. of three independent experiments, $t$-test, ${ }^{\star} P<0.01$ compared with WT mice). (c) APP co-localizes with AEP and EEA1. Primary neuronal cultures (DIV 12) were treated with 2 or $20 \mu \mathrm{M}$ of pre-aggregated $A \beta$ for $24 \mathrm{~h}$, followed by immunostaining with various antibodies including anti-AEP, anti-APP or anti-EEA1. A $\beta$ treatment increased the co-localization of APP and AEP in primary cortical neurons (left panels). APP co-localized with the endosomal marker EEA1 as well (right panels). Shown are the representative figures of two independent experiments. Scale bar, $10 \mu \mathrm{m}$. (d) A $\beta$ treatment elicits AEP activation in neurons in a dose-dependent manner. (e) Internalization assay showing the effect of $20 \mu \mathrm{M}$ A $\beta$ on APP endocytosis. (f) Co-immunoprecipitation of APP and AEP in WT and 5XFAD mouse brain. AEP in mouse brain lysates was immunoprecipitated with anti-AEP antibody and analysed by immunoblotting with anti-APP antibody. MW, molecular weight. 
a

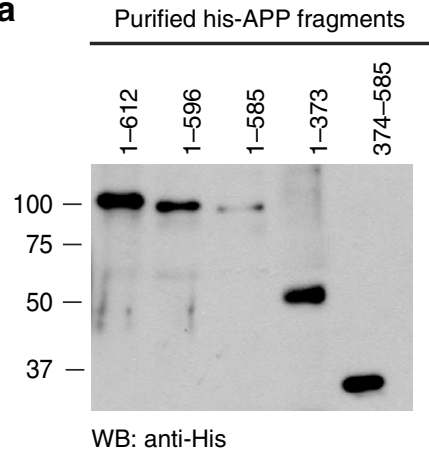

b

MAP2/TUNEL

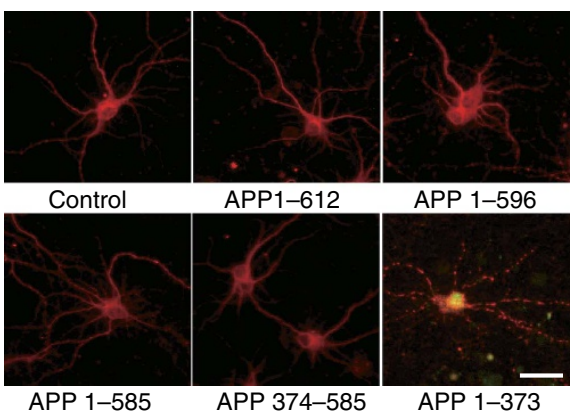

C

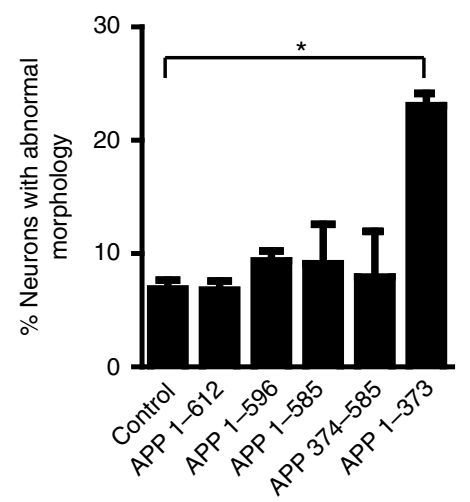

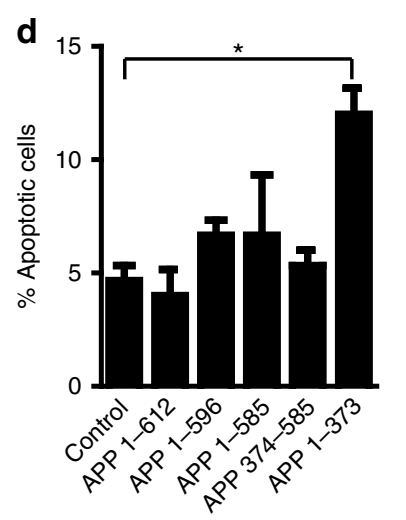
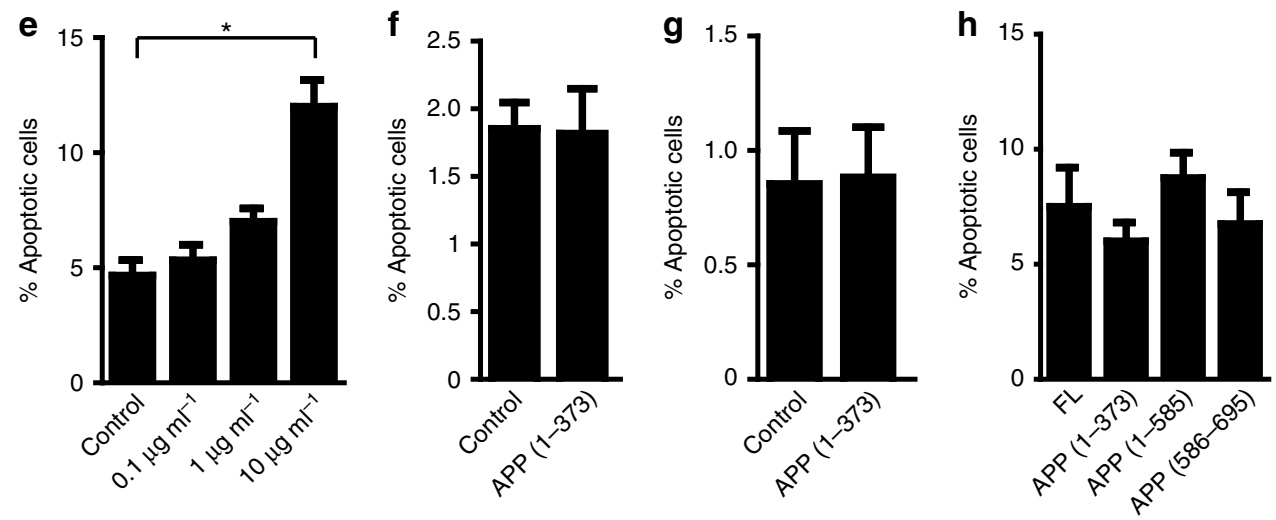

Figure 5 | The AEP-fragmented APP (1-373 induces neurodegeneration in primary cultured neurons. (a) Western blotting (WB) of the purified recombinant APP fragments. (b) Representative image of MAP2 and TUNEL staining after the neurons were incubated with APP fragments. Scale bar, $20 \mu \mathrm{m}$. (c) Percentage of neurons with abnormal morphology. Percentage of TUNEL-positive neurons induced by incubating with $10 \mu \mathrm{g} \mathrm{ml}^{-1}$ recombinant APP fragments (d) or different dose of APP $1-373$ fragment (e). Percentage of TUNEL-positive cells after PC12 cells (f) or HEK293 cells (g) were incubated with $10 \mu \mathrm{g} \mathrm{ml}^{-1} \mathrm{APP}_{1-373}$ fragment (mean \pm s.e.m.). (h) Percentage of TUNEL-positive neurons after infected with lentivirus encoding APP fragments. Data are mean \pm s.e.m. of three independent experiments, and were analysed using $t$-test $(\mathbf{f}, \mathbf{g})$ or one-way analysis of variance followed by post hoc comparison (c, d,e, $\mathbf{h}),{ }^{\star} P<0.01$.

autocleavage, with the activated component first detectable in mouse brain at 10 months of age, with further increases during ageing. There was a concomitant increase in the APP N-terminal and C-terminal fragments, with the $\mathrm{AEP}$-derived $\mathrm{APP}_{1-373}$, $\mathrm{APP}_{1-585}$ and $\mathrm{APP}_{586-695}$ highly enriched and tightly coupled to the temporal pattern of AEP activation (Fig. 6a). AEP enzymatic activity was also increased in an age-dependent manner, correlating with the presence of the mature active AEP protein (Fig. 6b). We observed similar age-dependent increases in AEP activity and APP cleavage patterns in spinal cord (Supplementary Fig. 8a). The AEP-derived 50-kDa N-terminal immunoreactive APP fragment was completely abolished in $\mathrm{AEP}^{-/-}$mice, even in the aged brain, supporting the hypothesis that APP processing during ageing is mediated by AEP (Fig. 6c). We further confirmed the cleavage of endogenous APP by knocking down AEP in HEK293 cells. The AEP-dependent cleavage fragments were found in control HEK293 cells, and were not detected when AEP was depleted by the siRNA (Supplementary Fig. 8b). In human brains, AEP-derived APP fragments $\mathrm{APP}_{1-373}, \mathrm{APP}_{1-585}$ and $\mathrm{APP}_{586-695}$ were all increased in $\mathrm{AD}$ cases compared with agematched controls. Active AEP fragments were also increased in $\mathrm{AD}$ brains than control brains (Fig. 6d). Enzymatic analysis demonstrated that AEP activity was also substantially increased in brains from both the 5XFAD mouse model of AD and in human $\mathrm{AD}$ cases (Fig. 6e,f). Immunohistochemistry showed a marked increase in intraneuronal AEP-derived $\mathrm{APP}_{586-695}$ immunoreactivity in the cortex and hippocampus in $\mathrm{AD}$ cases (Fig. 6g).
Although RNA-seq data suggest that AEP/LGMN is highly expressed in microglia ${ }^{29}$, immunohistochemistry staining shows that AEP immunoreactivity is also clearly enriched in neurons (Supplementary Fig. 8c). AEP and $\mathrm{APP}_{586-695}$ are also highly expressed in neurons of 5XFAD mouse brain as confirmed by confocal microscopy (Supplementary Fig. 8d,e). To investigate the relationship between the concentrations of AEP-derived APP fragments and A $\beta$, we developed an enzyme-linked immunosorbent assay (ELISA) using our cleavage-stie-specific antibodies and found that the concentrations of AEP-derived $\mathrm{APP}_{586-695}$ correlated with $\mathrm{A} \beta$ in $\mathrm{AD}$ and age-matched control brains (Supplementary Fig. 8f). Collectively, these findings indicate that AEP protein expression, autocleavage and enzyme activity are all upregulated during ageing, contributing to this novel APP processing event and increased $A \beta$ production.

Knockout of AEP reverses synaptic dysfunction in 5XFAD mice. Synaptic loss is believed to be the basis of cognitive impairment in the early phase of $\mathrm{AD}^{37}$. To assess the physiological role of AEP in this process, we crossed $\mathrm{AEP}^{-/-}$mice with $5 \mathrm{XFAD}$ mice to generate 5XFAD/AEP ${ }^{-1-}$ mice (Supplementary Fig. 9a). In $5 \mathrm{XFAD}$ mice, significant synaptic loss and behaviour deficits were detected at 5 months of age, in the absence of detectable neuronal $\operatorname{loss}^{38}$. Electron microscopic analysis revealed significant synapse loss in the CA1 region in 5XFAD mice compared with the agematched non-transgenic control mice and $\mathrm{AEP}^{-/-}$mice. Deletion of AEP in 5XFAD mice $\left(5 \mathrm{XFAD} / \mathrm{AEP}^{-/-}\right)$rescued 
a
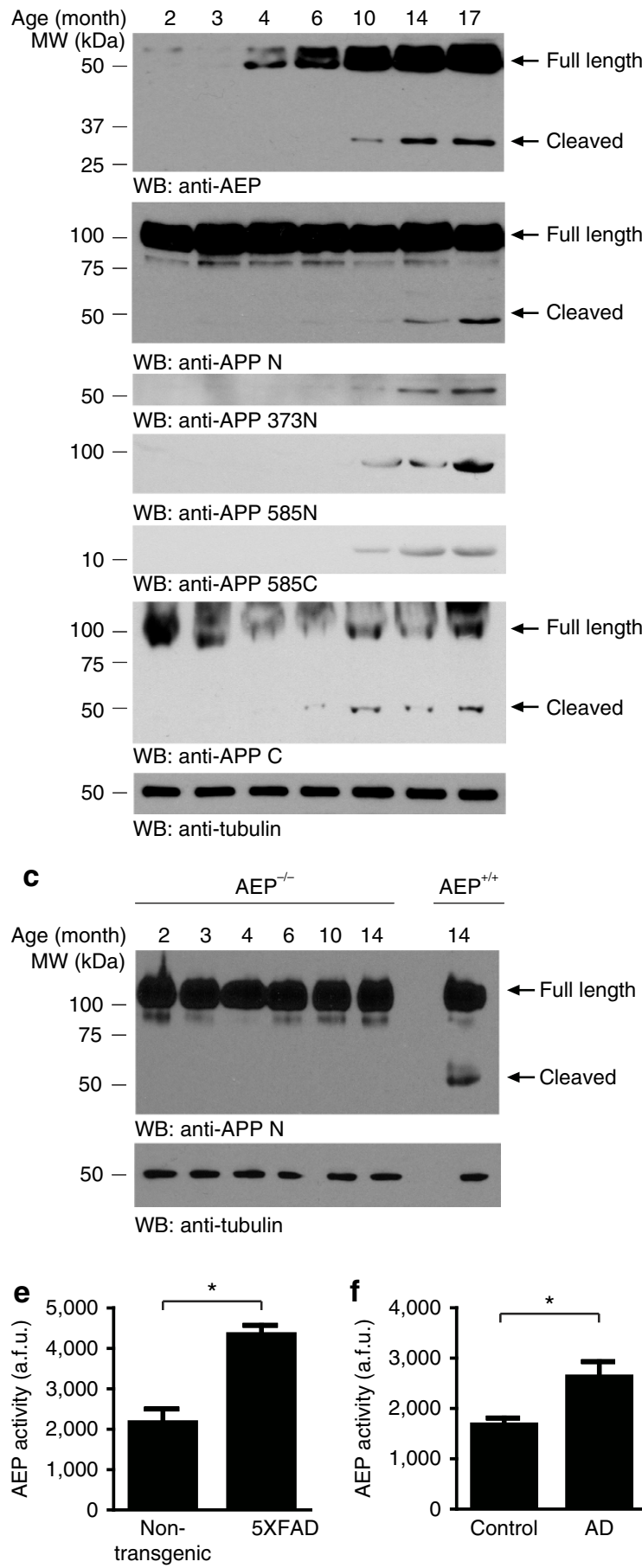

b

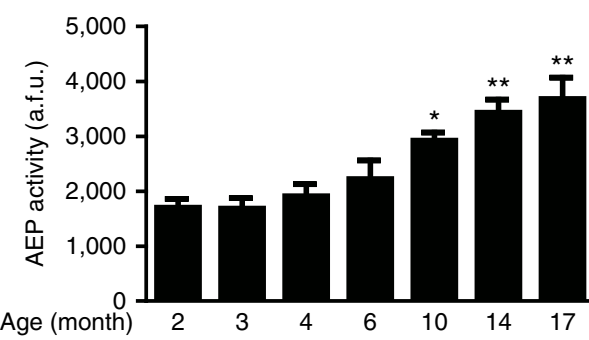

d
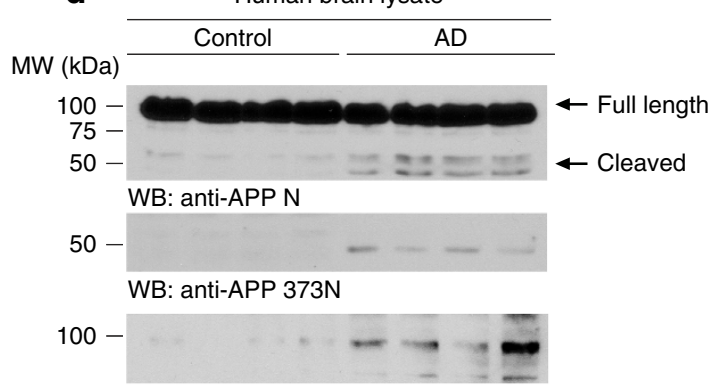

WB: anti-APP APP 585N
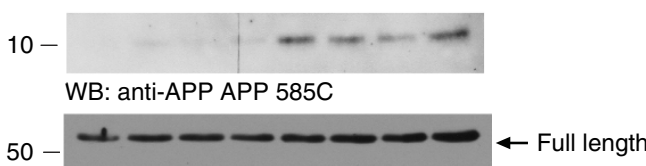

37

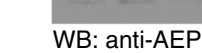

50

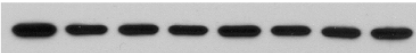

WB: anti-tubulin

g

Control
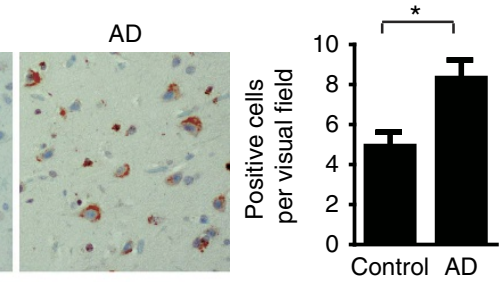

Cortex
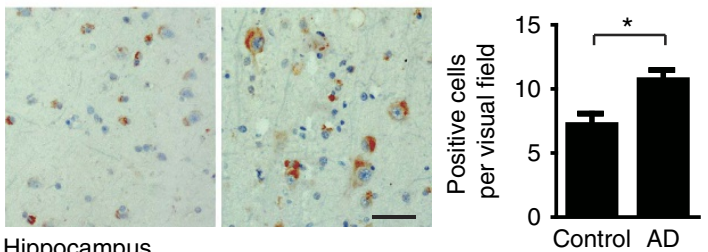

Figure 6 | AEP is upregulated and cleaves APP during ageing and in AD. (a) Western blot (WB) showing AEP and APP expressing and processing in mouse brain during ageing. (b) AEP enzymatic activity analysis (mean \pm s.e.m.; $n=6$; one-way analysis of variance (ANOVA), ${ }^{\star} P<0.01$ compared with $2-$,

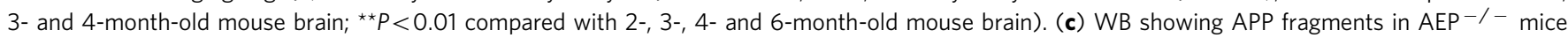
brain. (d) WB detection of APP processing in human brain samples from AD patients and age-matched controls. (e) AEP activity in 6-month-old 5XFAD mice and non-transgenic controls (mean \pm s.e.m.; $n=6$; $t$-test, ${ }^{\star} P<0.01$ ). (f) AEP activity in human brain samples from AD patients and age-matched controls (mean \pm s.e.m.; $n=6 ; t$-test, ${ }^{\star} P<0.01$ ). (g) Immunostaining showing the presence of AEP-derived APP fragments in AD brain (mean \pm s.e.m.; $t$-test, $\left.n=8 ;{ }^{\star} P<0.01\right)$. Scale bar, $50 \mu \mathrm{m}$. Data were analysed using one-way ANOVA followed by post hoc comparison.

the synapse loss (Fig. 7a and Supplementary Fig. 10a). We also assessed the density of dendritic spines along individual Golgi-stained pyramidal neurons. Spine density was decreased in 5XFAD mice model, and this defect was reversed in 5XFAD/ $\mathrm{AEP}^{-/-}$mice (Fig. $7 \mathrm{~b}$ and Supplementary Fig. 10b). 5XFAD mice display significantly impaired long-term potentiation (LTP) at Schaffer collateral-CA1 pathways ${ }^{39}$. Electrophysiological analysis demonstrated significantly increased LTP magnitude in 5XFAD/AEP ${ }^{-1-}$ mice when compared with 5XFAD mice. In contrast, LTP was comparable between the age-matched WT and $\mathrm{AEP}^{-1-}$ mice (Fig. 7c). Hence, these results show that inactivation of AEP rescues synaptic loss and LTP deficits in 5XFAD mice. 
a
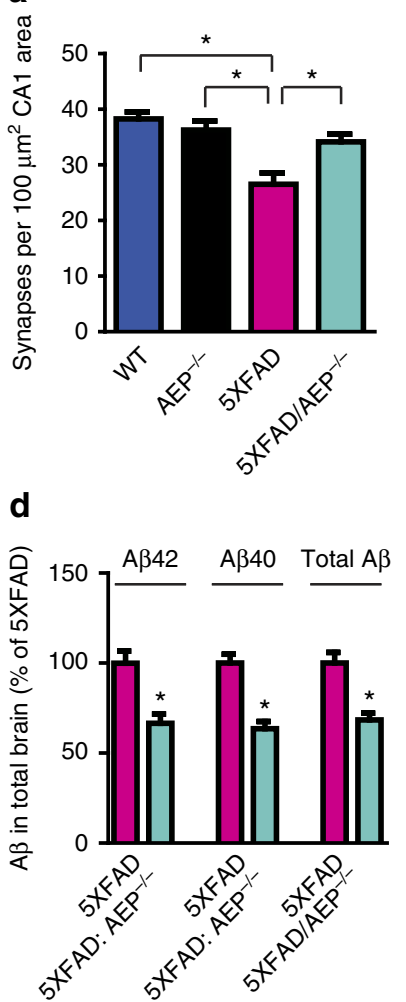

$\mathbf{f}$
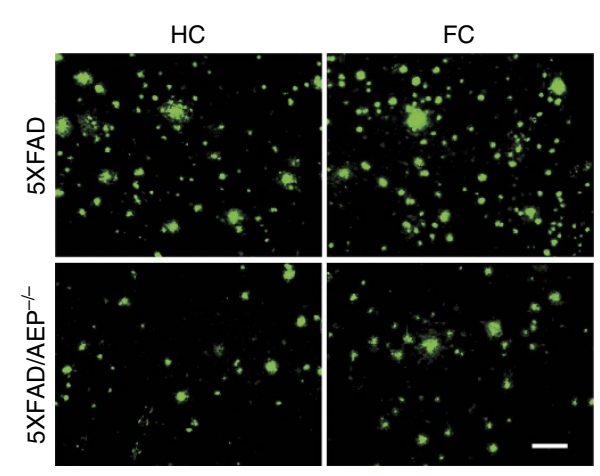

g
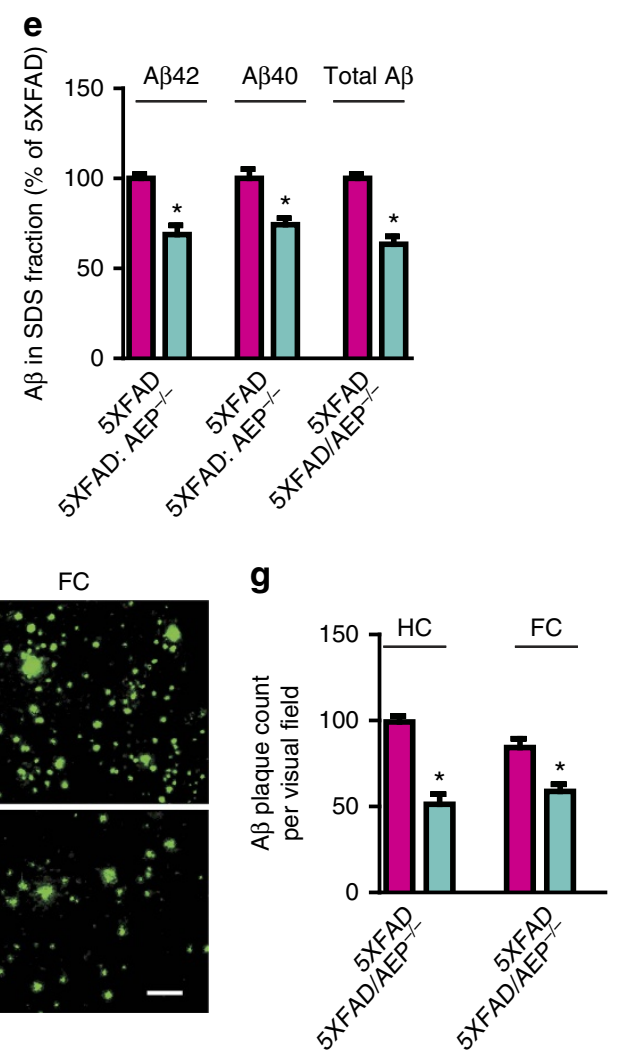

C

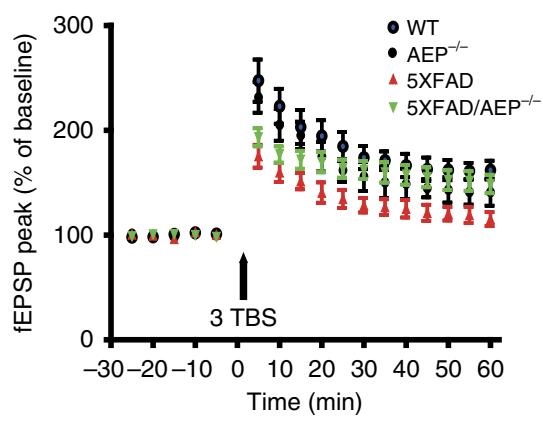

h
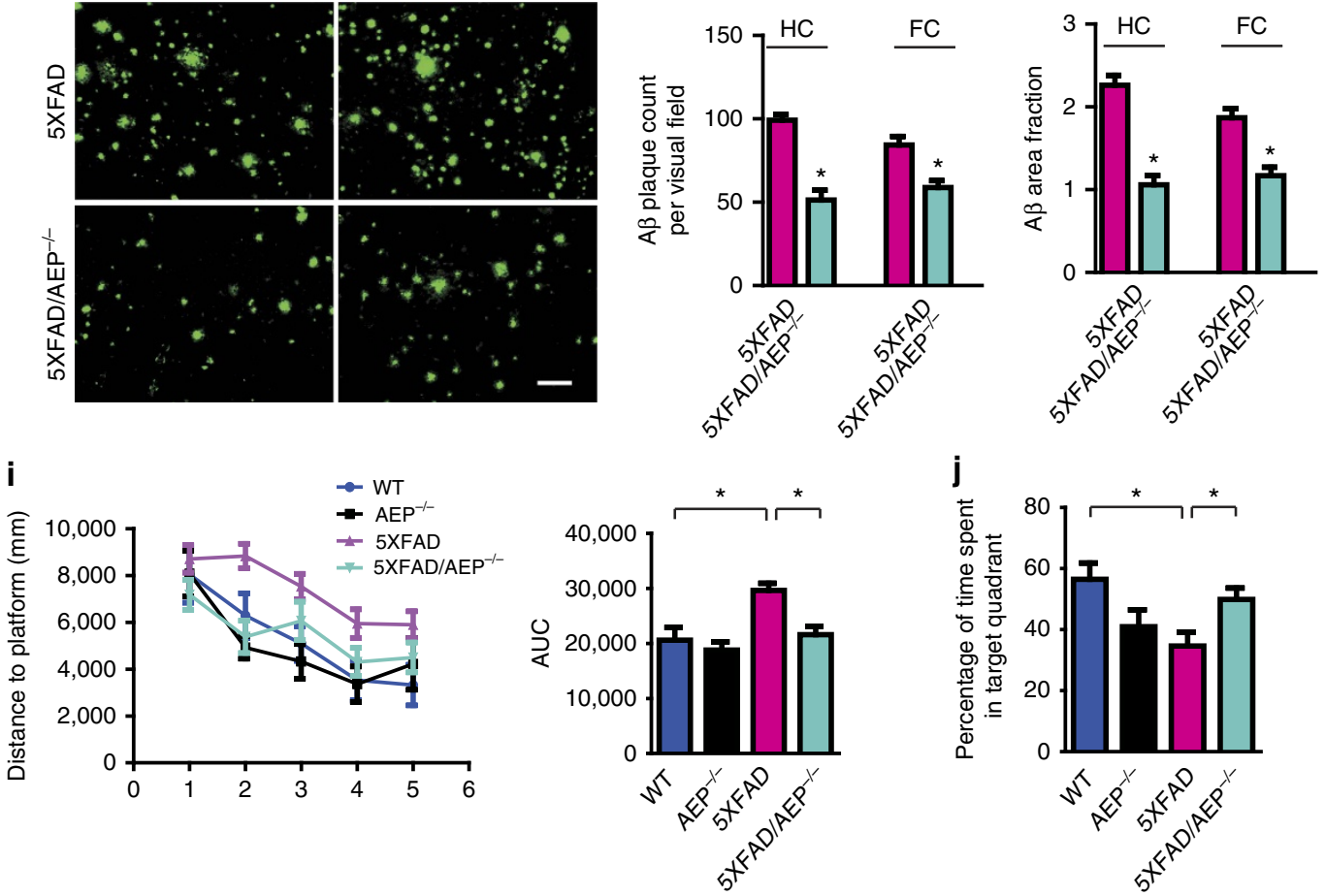

Figure 7 | AEP gene deficiency ameliorates synaptic dysfunction, A $\beta$ deposition and cognitive deficits in the 5XFAD mouse model. (a) The density of synapse determined by electron microscopy (mean \pm s.e.m.; $n=6$; ${ }^{\star} P<0.01$ ). (b) Spine density in the hippocampus determined by Golgi staining (mean \pm s.e.m.; $n=4 ;{ }^{\star} P<0.01$ ). (c) AEP deletion alleviates electrophysiological dysfunction in 5XFAD mice (mean \pm s.e.m.; $n=6$ in each group; ${ }^{\star} P<0.05$ ). (d,e) ELISA quantification of $A \beta$ in total brain lysates (d) or SDS fraction (e) from 6-month-old mice (mean \pm s.e.m.; $n=9$ in $5 X F A D, n=10$ in $5 X F A D / A E P^{-/}-$mice; $\left.{ }^{\star} P<0.01\right)$. (f) Thioflavin-S staining showing the A $\beta$ plaques in the hippocampus $(H C)$ and frontal cortex (FC). Scale bar, $50 \mu m$. $(\mathbf{g}, \mathbf{h})$ Quantification of number and surface area of $A \beta$ plaques (mean \pm s.e.m.; $n=6$; ${ }^{\star} P<0.01$ ). (i) Morris water maze analysis as distance travelled (millimetres) and integrated distance (area under the curve, AUC) for WT $(n=8)$, AEP $^{-/}-(n=8), 5 X_{F A D}(n=9)$ and 5XFAD/AEP $-/-(n=10)$ mice (mean \pm s.e.m.; ${ }^{\star} P<0.01$ ). (j) Probe trial result. Shown is the mean \pm s.e.m. percentage of time spent in the target quadrant $\left({ }^{\star} P<0.05\right)$. Data were analysed using $t$-test $(\mathbf{d}, \mathbf{e}, \mathbf{g}, \mathbf{h})$ or one-way analysis of variance followed by post hoc comparison $(\mathbf{a}, \mathbf{b}, \mathbf{c}, \mathbf{i}, \mathbf{j})$. TBS, theta-burst stimulation. 
Deletion of AEP ameliorates memory deficits in 5XFAD mice. To ascertain whether AEP influences the processing of APP and accumulation of $\mathrm{A} \beta$ peptides in vivo, we analysed total $\mathrm{A} \beta, \mathrm{A} \beta 40$ and $\mathrm{A} \beta 42$ in the brains of $5 \mathrm{XFAD} / \mathrm{AEP}^{-1}$ mice. We found $\sim 30 \%$ reduction in all $\mathrm{A} \beta$ peptide species in $5 \mathrm{XFAD} / \mathrm{AEP}^{-/-}$ mice compared with 5XFAD mice at 6 months of age. In addition, the highly aggregated, SDS-extractable forms of A $\beta$ peptides were also decreased in $5 \mathrm{XFAD} / \mathrm{AEP}^{-1-}$ mice (Fig. $7 \mathrm{~d}, \mathrm{e}$ ). Remarkably, the cerebral A $\beta$ level was lower in 5XFAD/AEP ${ }^{-/-}$ mice brain than in 5XFAD mice brain even at 1.5 months of age, before plaque deposition (Supplementary Fig. 10c). Thioflavin-S staining and $A \beta$ immunohistochemistry both revealed fewer $A \beta$ plaques in hippocampus and frontal cortex in 5XFAD/AEP $-1-$ versus 5XFAD mice. Quantification of the $A \beta$ plaque number and surface area demonstrated substantially reduced plaque burden in 5XFAD/AEP ${ }^{-1-}$ mouse brain (Fig. $7 f, g$ and Supplementary Fig. 10d,e). Immunoblotting analysis revealed that the AEPderived APP fragments in 5XFAD mice were diminished in 5XFAD/AEP ${ }^{-/-}$mice brain. APP and BACE1 expression levels were similar between 5XFAD and 5XFAD/AEP $-1-$ mice, but the C-terminal APP fragment (C99) resulting from BACE1 cleavage was decreased in $5 \mathrm{XFAD} / \mathrm{AEP}^{-/-}$mice. These results indicate that AEP deletion reduces $A \beta$ production by attenuating BACE1-mediated cleavage of APP (Supplementary Fig. 9b).

Next, we evaluated spatial memory abilities in 6-month-old WT, $\mathrm{AEP}^{-l-}, 5 \mathrm{XFAD}$ and $5 \mathrm{XFAD} / \mathrm{AEP}^{-l-}$ mice using the Morris water maze test. As expected, 5XFAD mice showed longer latency periods and longer swim path distance than WT mice, representing deficits in spatial memory formation. However, 5XFAD/ $\mathrm{AEP}^{-I-}$ mice were largely protected from spatial memory impairment (Fig. 7i and Supplementary Fig. 10f). All the mice exhibited comparable swim speeds, indicating that AEP gene knockout does not affect motor function (Supplementary Fig. 10g). 5XFAD/AEP ${ }^{-1}$ mice also performed better than 5XFAD mice on the probe test, spending more time in the target quadrant and indicating better memory recall (Fig. 7j). To verify that the behavioural effects of $5 \mathrm{XFAD} / \mathrm{AEP}^{-}{ }^{-}$- were not strain dependent, we also examined the rescue effect of AEP gene knockout in another well-established $\mathrm{AD}$ mouse model expressing two $\mathrm{AD}$ mutant genes, APP and PS1. APP/PS1/AEP ${ }^{-1-}$ mice at 15 months of age showed shorter latency periods and swim path distance than APP/PS1 mice during the training sessions, and spent more time in the target quadrant during the probe test (Supplementary Fig. 11a-d). Thus, AEP gene knockouts protect against memory deficits in two different AD mouse models.

Preserved memory in mice expressing uncleavable APP. To confirm the role of AEP-mediated APP cleavage in the pathogenesis of $\mathrm{AD}$, we injected WT mice with adeno-associated virus (AAVs) encoding human mutant $\mathrm{APP}_{\mathrm{SLA}}$ expressing the Swedish, London and Austrian mutations that are associated with early-onset familial $\mathrm{AD}^{40}$ or an $\mathrm{AEP}$-uncleavable form

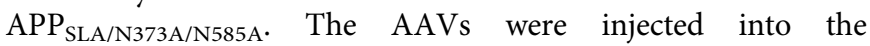
hippocampus, where they expressed the embedded cDNA specifically in pyramidal neurons under control of the human synapsin-1 promoter. The expression levels of $\mathrm{APP}_{\mathrm{SLA}}$ and $\mathrm{APP}_{\mathrm{SLA} / \mathrm{N} 373 \mathrm{~A} / \mathrm{N} 585 \mathrm{~A}}$ were similar 6 months after the intracerebral injection of the AAVs as indicted by immunohistochemistry and western blot using an antibody specific to human APP (Fig. 8a,b). In the Morris water maze probe test, the $\mathrm{APP}_{\mathrm{SLA} / \mathrm{N} 373 \mathrm{~A} / \mathrm{N} 585 \mathrm{~A}}$ mice spent more time in the target quadrant than did the APP ${ }_{\text {SLA }}$ mice, indicating preserved cognitive function (Fig. 8c). Expression of $\mathrm{APP}_{\text {SLA }}$ caused significant synaptic loss in the hippocampus, while the AEP-uncleavable N373A/N585A mutations ameliorated the synaptic loss (Fig. 8d). Electrophysiological analysis found that the paired pulse ratio was preserved in $\mathrm{APP}_{\mathrm{SLA} / \mathrm{N} 373 \mathrm{~A} / \mathrm{N} 585 \mathrm{~A}}$

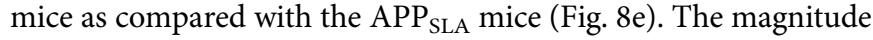
of LTP was also significantly elevated in mice expressing uncleavable $\mathrm{APP}_{\mathrm{SLA} / \mathrm{N} 373 \mathrm{~A} / \mathrm{N} 585 \mathrm{~A}}$ (Fig. 8f). Furthermore, the slope of $\mathrm{I} / \mathrm{O}$ curve was preserved in the $\mathrm{APP}_{\mathrm{SLA} / \mathrm{N} 373 \mathrm{~A} / \mathrm{N} 585 \mathrm{~A}}$ mice (Fig. 8g). Collectively, these results strongly support that the AEP-mediated processing of APP plays critical roles in the pathogenesis of $\mathrm{AD}$.

\section{Discussion}

In the present study, we have identified AEP as a novel pro-amyloidogenic protease cleaving the APP ectodomain at both N373 and N585 sites. AEP cleavage of APP at N585 enhances subsequent BACE1 processing of the AEP-generated APP stub ( $\left.\mathrm{APP}_{586-695}\right)$, increasing $\mathrm{A} \beta$ levels. The AEP-generated $\mathrm{N}$-terminal ectodomain of $\mathrm{APP}_{1-373}$ triggers neurodegeneration, indicating that AEP activation may induce neuronal cell death through proteolytic processing of APP. Blockade of AEP processing of APP in a variety of paradigms protects against A $\beta$ accumulation, synaptic loss and behavioural deficits. Since AEP expression and activation is elevated in brain in an agedependent manner, and leads to increased cleavage of APP in aged brains (Fig. 6), we propose that AEP contributes to the strong effect of ageing on AD risk. Collectively, these observations provide a rationale for the development of AEP inhibitors for treating $\mathrm{AD}$.

The accumulation of $\mathrm{A} \beta$ in $\mathrm{AD}$ brain is caused by an imbalance between its production and clearance ${ }^{41}$. There is direct evidence that $\mathrm{A} \beta$ clearance is impaired in late-onset sporadic $\mathrm{AD}^{42}$. On the other hand, there is also evidence demonstrating increased production of $\mathrm{A} \beta$ in familial Alzheimer's disease caused by Swedish mutation of $\mathrm{APP}^{43}$. Late-onset sporadic $\mathrm{AD}$ cases show elevated BACE1 levels, which is the rate-limiting enzyme for $\mathrm{A} \beta$ production. The elevation of BACE1 activity is correlated with brain $\mathrm{A} \beta$ loads $\mathrm{s}^{44,45}$. Since human clinical trials of improving $\mathrm{A} \beta$ clearance for $\mathrm{AD}$ have failed $^{46,47}, \mathrm{~A} \beta$ clearance defects might not be the major or sole contributor to $\mathrm{AD}$ onset and progression. Our study supports a pathogenic model in which AEP levels and activity increase with age, creating a novel cleavage of APP that increases BACE1 processing and $A \beta$ production under physiological conditions in neurons in vitro and in vivo.

APP is processed by $\alpha-, \beta$ - and $\gamma$-secretases, generating amyloidogenic and non-amyloidogenic fragments. Secretaseindependent processing pathways may also exist, in that the half-life of APP is very short and since not all APP is secreted ${ }^{48}$. APP is also a substrate of caspases ${ }^{30,49}$, but the impact of this processing on $\mathrm{A} \beta$ generation and/or $\mathrm{AD}$ pathology is still not well established $^{50}$. APP is degraded in the lysosomes ${ }^{51,52}$, presumably mediated at least in part by lysosomal enzymes such as AEP or cathepsins. Interestingly, cathepsin B cleaves APP at $\beta$-secretase cleavage site $\mathrm{s}^{31,53,54}$. Here we provide both molecular and biochemical evidence showing that AEP may act as a novel $\delta$-secretase that mediates the proteolytic processing of APP.

Where does AEP processing APP occur? It has been shown previously that lysosomal enzymes are abnormally distributed in human $\mathrm{AD}$ patient brains ${ }^{55}$. AEP usually resides in endolysosomes in healthy cells, but it is secreted extracellularly or may be leaked into the cytoplasm in cancer cells, aged cells and in $\mathrm{AD}$ neurons ${ }^{21,26}$. We found that AEP co-fractionates with BACE1 and APP along with endolysosomal markers and that it binds APP in mouse brain (Fig. 4). Fitting with these observations, A $\beta$ treatment also elicits AEP co-localization with APP in primary neurons (Fig. 4c). AEP is secreted extracellularly, and associates with APP on the cell surface. Cell surfaceassociated AEP can be internalized and processed to its active form (Supplementary Fig. 7). 
a

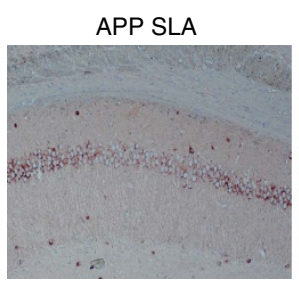

IHC: anti-APP (human)

d

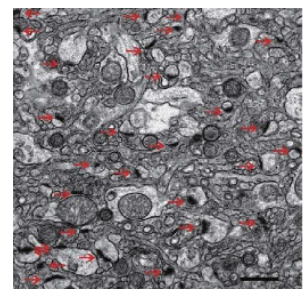

Control
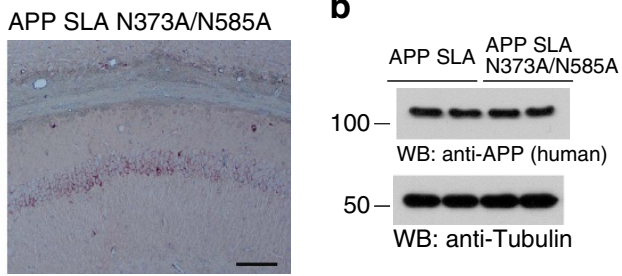

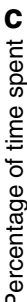
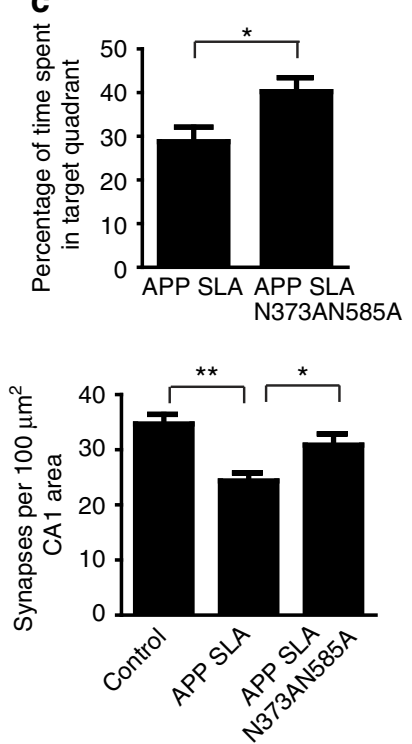

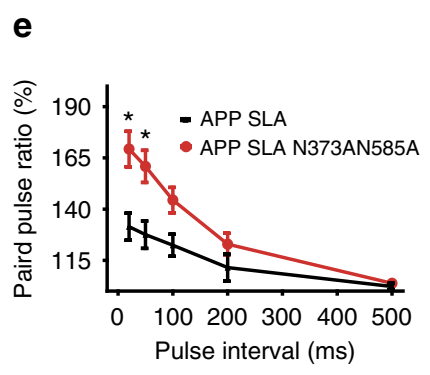

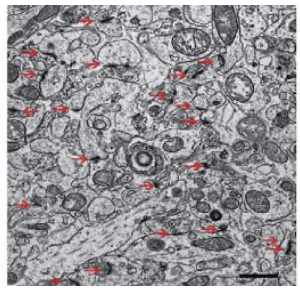

APP SLA

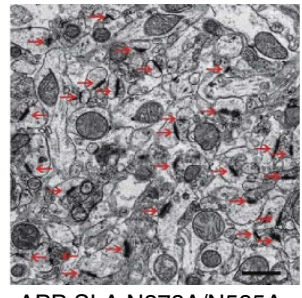

APP SLA N373A/N585A f

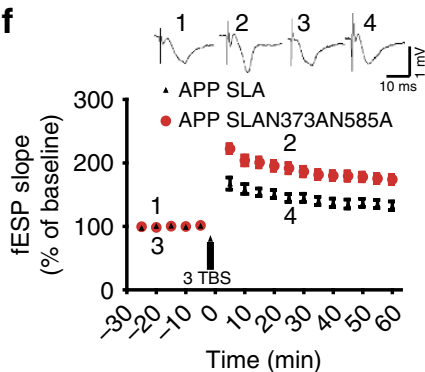

g

g

Stimulus (V)

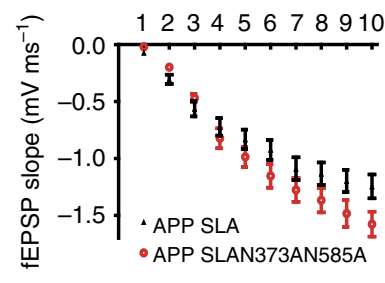

h
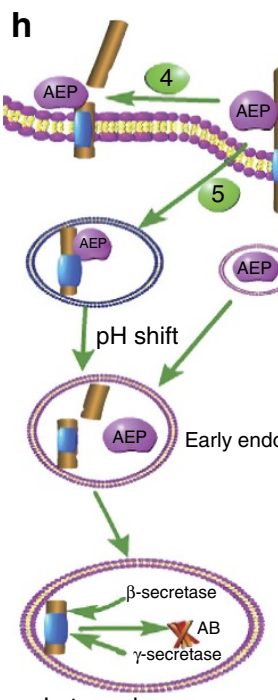

Late endososome
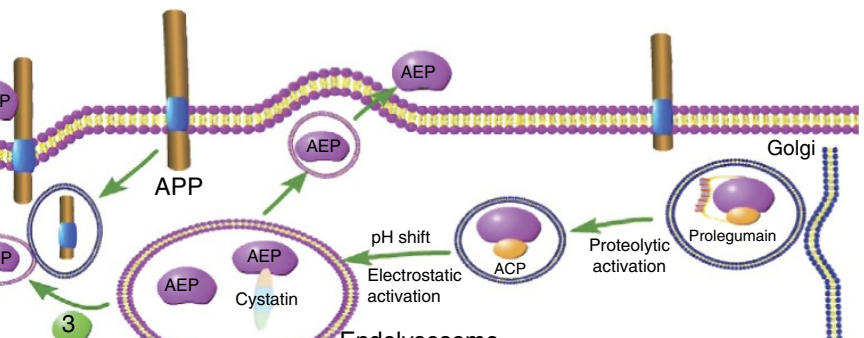

APP

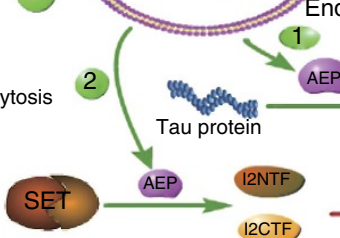

AEP Tau fragment Hyperphosphorylation NFT

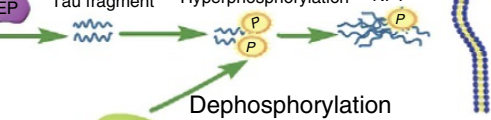

PP2A

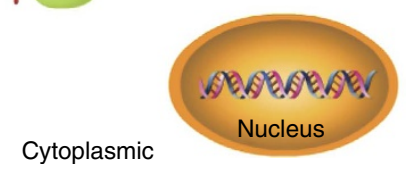

Figure 8 | Blockade of AEP cleavage prevents synaptic and cognitive dysfunction induced by APP SLA. (a,b) AAV-mediated expression of human APP SLA and APP SLA N373AN585A detected by immunohistochemistry and western blot (WB) using an antibody specific to human APP. Scale bar, $100 \mu$ m. (c) Probe trial of Morris water maze test showing blockade of AEP cleavage prevents memory deficits induced by APP SLA (mean \pm s.e.m.; ${ }^{\star} P<0.05$ ). (d) The synaptic density in the hippocampus of mice injected with AAV-APP SLA and AAV-APP SLA N373AN585A determined by electron microscopy (mean \pm s.e.m.; $\left.n=6 ;{ }^{\star} P<0.05,{ }^{\star} \times P<0.01\right)$. Scale bar, $1 \mu \mathrm{m}$. (e-j) Blockade of AEP cleavage preserves the electrophysiological function. The APP SLA N373AN585A mice showed higher ratio of paired pulse (e), higher averaged magnitude of LTP (f) and higher slope of I/O curve ( $\mathbf{g}$ ) than the APP SLA N373AN585A mice. (h) Possible pathways for AEP-mediated cleavage of APP, tau and SET in AD. (1) AEP might translocate from the endolysosome into the cytoplasmic space, where it cleaves tau; (2) intracellular AEP cuts SET, leading to PP2A inhibition and consequent tau hyperphosphorylation;

(3) intracellular AEP can be fused with the endocytosed APP; (4) activated AEP might be secreted extracellularly, where it interacts with the ectodomain of APP; (5) AEP and APP can also form a complex, which can be internalized via endocytosis. Data were analysed using $t$-test (c,e,f,g) or one-way analysis of variance followed by post hoc comparison (d). 
Given that APP cleavage by AEP promotes the subsequent BACE1 processing of $\mathrm{APP}_{586-695}$ via release of steric hindrance and more access to the substrate, AEP might act as an upstream/ initiating trigger for APP amyloidogenic processing. Since A $\beta$ processing is mainly mediated by BACE1 and $\gamma$-secretase, deletion of the upstream $\delta$-secretase predominantly impairs APP cleavage efficiency by BACE1. In addition to APP, AEP also cleaves other substrates implicated in AD including tau and SET $\left(\mathrm{I}_{2}^{\mathrm{PP} 2 \mathrm{~A}}\right)^{19,21,23}$. The reduction of $\mathrm{A} \beta$ levels in 5XFAD/AEP ${ }^{-/-}$ mice rescues spine density, LTP and cognition (Fig. 7).

On the basis of these findings, we propose the following model. During ageing and other cellular stressors in the AD brain, AEP translocates from the endolysosome into the cytoplasmic space, where it cleaves tau, resulting in truncated neurotoxic fragments, hyperphosphorylation and neurofibrillar tangle formation ${ }^{23}$. Moreover, AEP cleaves SET, leading to PP2A inhibition and accelerates tau hyperphosphorylation ${ }^{21}$. AEP is also secreted extracellularly and distributes in the CSF (Supplementary Fig. 7a). During the ageing process and in $\mathrm{AD}$, the reduction in brain $\mathrm{pH}$ decreases and reduced cystatin $C$ levels both promote AEP protease enzymatic activation. The secreted AEP binds APP on the plasma membrane and cleaves APP at N373 and N585 residues, shedding a neurotoxic $\mathrm{APP}_{1-373}$ fragment. The AEP/APP complex may also be internalized via endocytosis, with the AEP further activated in the low-pH environment of the endosome, cleaving APP at the N585 site. The resultant $\mathrm{APP}_{586-695}$ fragment subsequently serves as an optimal substrate for BACE1, augmenting amyloid formation (Fig. 8h). Consequently, the activated AEP and reduced inhibitory cystatin $\mathrm{C}$ levels in $\mathrm{AD}$ brains coordinately result in amyloid deposition and aggregation.

AEP expression and activity have been linked to a number of pathological conditions including atherosclerosis, cancer, stroke and neurodegenerative diseases ${ }^{19,21,56-58}$. Despite large-scale efforts to therapeutically target putative disease mechanisms in $\mathrm{AD}$, such as $\mathrm{A} \beta$ production or clearance, neuroprotective treatments are still lacking. There is growing consensus that gaining a better understanding of the underlying disease mechanisms is urgently needed. Our findings provide substantial in vitro and in vivo evidence demonstrating that blockade of AEP cleavage of APP reduces A $\beta$ production and amyloid deposition, underscoring that $\delta$-secretase activity by AEP plays a crucial role in APP metabolism and in AD pathogenesis. Since $\delta$-secretase cleaves both APP and tau in an age-dependent manner and mediates the amyloid plaque and NFT pathology onset $^{23}$, our findings highlight a previously unappreciated role of this novel secretase in $\mathrm{AD}$ progression. Because this enzyme also cleaves TDP-43 (ref. 22), this $\delta$-secretase might also contribute to other age-dependent neurodegenerative diseases including some forms of frontotemporal lobar degeneration and amyotrophic lateral sclerosis. Hence, inhibition of AEP may be a novel therapeutic strategy for treating several pathogenic mechanisms that contribute to $\mathrm{AD}$ and other neurodegenerative diseases.

\footnotetext{
Methods

Transgenic mice. 5XFAD mice and APP/PS1 mice on a C57BL/6J background were obtained from the Jackson Laboratory (Stock No. 006554 and 004462 , respectively). AEP knockout mice on a mixed C57BL/6 and 129/Ola background were generated as reported ${ }^{18}$. Only male mice were used. All mice were housed under standard conditions at $22^{\circ} \mathrm{C}$ and a 12-h light:dark cycle with free access to food and water. Animal care and handling was performed according to the Declaration of Helsinki and the Emory Medical School Guidelines. The following animal groups were analysed: WT, $\mathrm{AEP}^{-/-}, 5 \mathrm{XFAD}, 5 \mathrm{XFAD}^{-\mathrm{AEP}^{-}}{ }^{-}, \mathrm{APP} / \mathrm{PS} 1$ and APP/PS1/AEP $-1-$. Sample size was determined by Power and Precision (Biostat). Investigators were blinded to the group allocation during the animal experiments. The protocol was reviewed and approved by the Emory Institutional
} Animal Care and Use Committee.
Human tissue samples. Post-mortem brain samples were dissected from frozen brains of eight $\mathrm{AD}$ cases (age $74.5 \pm 11.2$ years, mean \pm s.d.) and eight non-demented controls (age 73.9 \pm 12.7 years) from the Emory Alzheimer's Disease Research Center. Informed consent was obtained from all subjects. The study was approved by the Emory University CND Tissue Committee. AD was diagnosed according to the criteria of the Consortium to Establish a Registry for $\mathrm{AD}$ and the National Institute on Aging. Diagnoses were confirmed by the presence of amyloid plaques and neurofibrillary tangles in formalin-fixed tissue. The post-mortem interval was similar between the AD group and control group.

Antibodies and reagents. Antibodies to the following targets were used: anti-APP $\mathrm{N}$-terminal antibody (clone 22C11, 1:1,000, Calbiochem), myc (1:1,000, Calbiochem), anti-APP C-terminal antibody (1:500, CT15, from Dr Edward Koo University of California $\left.{ }^{59}\right)$, GFP (1:1,000, Santa Cruz), and LAMP1 (1:500, Santa Cruz), GST-horseradish peroxidase (HRP), $\beta$-tubulin III, tubulin, MAP2 and A $\beta$ (all 1:1,000, Sigma-Aldrich), presenilin-1 (1:500, Abcam), BACE1, (1:1,000, Cell Signaling), GGA3 (1:500, Cell Signaling), EEA1 (1:500, Cell Signaling), AEP antibody clone 6E3 (1:1,000, from Dr Colin Watts, University of Dundee $\left.{ }^{17}\right)$, human AEP antibody (1:200, R\&D) and $\operatorname{sAPP} \alpha(1: 1,000, \mathrm{MBL})$. Inhibitors were used against: caspase $(20 \mu \mathrm{M}$ ZVAD-fmk, Calbiochem), $\alpha$-secretase $(10 \mu \mathrm{M}$ TAPI-1, Calbiochem), $\beta$-secretase (50 nM KTEETSEVN(stat)VAEF, Calbiochem), $\gamma$-secretase $(25 \mu \mathrm{M}$ DAPT, Calbiochem) and cathepsin $(10 \mu \mathrm{M}$ E64, SigmaAldrich). Histostain-SP, mouse and human A $\beta 40$ and A $\beta 42$ ELISA kits were purchased from Invitrogen. Total A $\beta$ chemiluminescent ELISA kit was purchased from Covance. The In Situ Cell Death Detection Kit was purchased from Roche. Recombinant AEP was purchased from Novoprotein. The recombinant AEP was first activated by incubation in activation buffer $(0.1 \mathrm{M} \mathrm{NaOAc}, 0.1 \mathrm{M} \mathrm{NaCl}, \mathrm{pH}$ $4.5)$ at $37^{\circ} \mathrm{C}$ for $4 \mathrm{~h}$. Recombinant BACE1 was purchased from Sigma-Aldrich. Recombinant ADAM10 was purchased from R\&D. Z-Ala-Ala-Asn-AMC was purchased from Bachem. All chemicals not included above were purchased from Sigma-Aldrich.

In vitro APP cleavage assay. To assess the cleavage of APP by AEP in vitro, HEK293 cells (obtained from the American Type Culture Collection (ATCC)) were transfected with $10 \mu \mathrm{g}$ GFP-APP or GST-APP plasmids by the calcium phosphate precipitation method. Forty-eight hours after transfection, the cells were collected, washed once in PBS, lysed in lysis buffer $(50 \mathrm{mM}$ sodium citrate, $5 \mathrm{mM}$ dithiothreitol (DTT), 0.1\% CHAPS and 0.5\% Triton X-100, pH 7.4), and centrifuged for $10 \mathrm{~min}$ at $14,000 \mathrm{~g}$ at $4{ }^{\circ} \mathrm{C}$. The supernatant was then incubated with mouse kidney lysates at $\mathrm{pH} 7.4$ or 6.0 at $37^{\circ} \mathrm{C}$ for $30 \mathrm{~min}$. To measure the cleavage of purified APP fragments by AEP, BACE1 or ADMA10, GST-tagged APP full length or fragments were purified with glutathione beads. The purified APP was incubated with recombinant AEP $\left(5 \mu \mathrm{g} \mathrm{ml}^{-1}\right)$ in AEP buffer $(50 \mathrm{mM}$ sodium citrate, $5 \mathrm{mM}$ DTT, $0.1 \%$ CHAPS and $0.5 \%$ Triton X-100, $\mathrm{pH} 6.0$ ), recombinant BACE1 $\left(100 \mathrm{U} \mathrm{ml}^{-1}\right)$ in BACE1 buffer $(20 \mathrm{mM}$ sodium acetate, $0.1 \%$ Triton $\mathrm{X}-100, \mathrm{pH} 4.5)$, or recombinant ADAM10 $\left(1 \mathrm{ng} \mathrm{\mu l}^{-1}\right)$ in ADAM10 buffer $(25 \mathrm{mM}$ Tris, $2 \mu \mathrm{M} \mathrm{ZnCl}_{2}, 0.005 \%$ Brij-35, pH 9.0) for $30 \mathrm{~min}$. The samples were then boiled in $1 \times$ SDS loading buffer and analysed by immunoblotting.

AEP activity assay. Tissue homogenates or cell lysates $(10 \mu \mathrm{g})$ were incubated in $200 \mu \mathrm{l}$ assay buffer $\left(20 \mathrm{mM}\right.$ citric acid, $60 \mathrm{mM} \mathrm{Na}_{2} \mathrm{HPO}_{4}, 1 \mathrm{mM}$ EDTA, $0.1 \%$ CHAPS and $1 \mathrm{mM}$ DTT, pH 6.0) containing $20 \mu \mathrm{M}$ AEP substrate Z-Ala-Ala-Asn-AMC (Bachem). AMC released by substrate cleavage was quantified by measuring at $460 \mathrm{~nm}$ in a fluorescence plate reader at $37^{\circ} \mathrm{C}$ for $1 \mathrm{~h}$ in kinetic mode. The activity of AEP was expressed as the reading at $1 \mathrm{~h}$ minus the first reading.

Western blot analysis. The mouse brain tissue or human tissue samples were lysed in lysis buffer (50 mM Tris, pH 7.4, $40 \mathrm{mM} \mathrm{NaCl}, 1 \mathrm{mM}$ EDTA, 0.5\% Triton $\mathrm{X}-100,1.5 \mathrm{mM} \mathrm{Na}_{3} \mathrm{VO}_{4}, 50 \mathrm{mM} \mathrm{NaF}, 10 \mathrm{mM}$ sodium pyrophosphate and $10 \mathrm{mM}$ sodium $\beta$-glycerophosphate, supplemented with protease inhibitors cocktail), and centrifuged for $15 \mathrm{~min}$ at $16,000 \mathrm{~g}$. The supernatant was boiled in SDS loading buffer. After SDS-PAGE, the samples were transferred to a nitrocellulose membrane. Western blot analysis was performed with a variety of antibodies. Images have been cropped for presentation. Full-size images are presented in Supplementary Fig. 12 .

Co-immunoprecipitation. The mouse brain tissue samples were lysed in lysis buffer and centrifuged for $15 \mathrm{~min}$ at $16,000 \mathrm{~g}$. The supernatant was incubated with anti-AEP antibody and protein A/G-agarose overnight at $4{ }^{\circ} \mathrm{C}$. After extensive washing, the bound proteins were eluted from the beads by boiling in Laemmli sample buffer and subjected to western blot analyses.

Subcellular fractionation. Subcellular fractionation of mouse brain tissues was performed as described previously ${ }^{60}$. Briefly, $150 \mathrm{mg}$ frontal cortex tissue was minced with a scalpel blade in $1 \mathrm{ml}$ of homogenization buffer $(0.25 \mathrm{M}$ sucrose, $1 \mathrm{mM} \mathrm{MgCl}_{2}, 10 \mathrm{mM}$ Tris-HCl, pH 7.4, supplemented with protease inhibitor 
cocktail). The buffer was discarded after centrifugation at $100 \mathrm{~g}$ for $2 \mathrm{~min}$. The tissues were suspended in $1.5 \mathrm{ml}$ homogenization buffer and homogenized by successive passages through needles of increasing gauge number (19-26). The suspension was centrifuged at $1,000 \mathrm{~g}$ for $10 \mathrm{~min}$ to discard nuclei and cellular debris. The supernatant was adjusted to $1.4 \mathrm{M}$ sucrose, and incorporated into a discontinuous sucrose gradient consisting of the four following layers: $2 \mathrm{ml} 2 \mathrm{M}$ sucrose, $2.25 \mathrm{ml} 1.4 \mathrm{M}$ sucrose, $3.75 \mathrm{ml} 1.2 \mathrm{M}$ sucrose and $5 \mathrm{ml} 0.8 \mathrm{M}$ sucrose. The gradients were centrifuged for $2.5 \mathrm{~h}$ at $100,000 \mathrm{~g}$. Thirteen fractions were collected from the top of the gradient and stored as aliquots at $-80^{\circ} \mathrm{C}$. Equal volumes of each fraction were boiled in $1 \times$ SDS loading buffer and analysed by immunoblotting.

Mass spectrometry analysis. Protein samples were in-gel digested with trypsin. Peptide samples were resuspended in loading buffer $(0.1 \%$ formic acid, $0.03 \%$ trifluoroacetic acid and $1 \%$ acetonitrile) and loaded onto a $20-\mathrm{cm}$ nano-highperformance liquid chromatography column (internal diameter $100 \mu \mathrm{m}$ ) packed with Reprosil-Pur $120 \mathrm{C} 18-\mathrm{AQ} 1.9 \mu \mathrm{m}$ beads (Dr. Maisch) and eluted over a $2 \mathrm{~h}$ $4-80 \%$ buffer B reverse phase gradient (buffer A: $0.1 \%$ formic acid and $1 \%$ acetonitrile in water; buffer B: $0.1 \%$ formic acid in acetonitrile) generated by a NanoAcquity UPLC system (Waters Corporation). Peptides were ionized with $2.0 \mathrm{kV}$ electrospray ionization voltage from a nano-ESI source (Thermo) on a hybrid LTQ XL Orbitrap mass spectrometer (Thermo). Data-dependent acquisition of centroid MS spectra at 30,000 resolution and MS/MS spectra were obtained in the LTQ following collision-induced dissociation (collision energy 35\%, activation Q 0.25 , activation time $30 \mathrm{~ms}$ ) for the top 10 precursor ions with charge determined by the acquisition software to be $z \geq 2$. Dynamic exclusion of peaks already sequenced was for $20 \mathrm{~s}$ with early expiration for two count events with signal to noise $>2$. Automatic gating control was set to $150 \mathrm{~ms}$ maximum injection time or 106 counts. To identify AEP cleavage sites on human APP, the SageN Sorcerer SEQUEST 3.5 algorithm was used to search and match MS/MS spectra to a complete semi-tryptic human proteome database (NCBI reference sequence revision 50 , with 66,652 entries) plus pseudo-reversed decoys sequences ${ }^{61,62}$ with a 20 p.p.m. mass accuracy threshold. Only $b$ - and $y$-ions were considered for scoring (Xcorr) and Xcorr along with $\Delta \mathrm{Cn}$ were dynamically increased for groups of peptides organized by a combination of trypticity (fully or partial) and precursor ion charge state to remove false-positive hits along with decoys until achieving a false-discovery rate (FDR) of $<5 \%(<0.25 \%$ for proteins identified by more than one peptide). The FDR was estimated by the number of decoy matches (nd) and total number of assigned matches (nt). FDR $=2 \times \mathrm{nd} / \mathrm{nt}$, assuming mismatches in the original database were the same as in the decoy database. To detect the AEP-derived APP fragments, AD brain lysates were immunoprecipitated with anti-APP N-terminal antibody and subjected to proteomic analysis. All semi-tryptic MS/MS spectra for putative AEP-generated APP cleavage sites were manually inspected.

Immunohistochemistry. Free-floating $30-\mu \mathrm{m}$-thick serial sections were treated with $0.3 \%$ hydrogen peroxide for $10 \mathrm{~min}$. Then, sections were washed three times in PBS and blocked in 1\% BSA and $0.3 \%$ Triton X-100, for 30 min followed by overnight incubation with primary antibodies at $4{ }^{\circ} \mathrm{C}$. The signal was developed using Histostain-SP kit according to the manufacturer's instructions.

A $\beta$ plaque histology. Amyloid plaques were stained with Thioflavin-S. Free-floating $40-\mu \mathrm{m}$ brain sections were incubated in $0.25 \%$ potassium permanganate solution for $20 \mathrm{~min}$, rinsed in distilled water and incubated in bleaching solution containing $2 \%$ oxalic acid and $1 \%$ potassium metabisulfite for $2 \mathrm{~min}$. After rinsed in distilled water, the sections were transferred to blocking solution containing $1 \%$ sodium hydroxide and $0.9 \%$ hydrogen peroxide for $20 \mathrm{~min}$. The sections were incubated for $5 \mathrm{~s}$ in $0.25 \%$ acidic acid, then washed in distilled water and stained for $5 \mathrm{~min}$ with $0.0125 \%$ Thioflavin-S in $50 \%$ ethanol. The sections were washed with $50 \%$ ethanol and placed in distilled water. Then the sections were covered with a glass cover using mounting solution and examined under a fluorescence microscope. The plaque number and plaque area were calculated using ImageJ software (National Institutes of Health).

Generation of AEP-derived APP fragment antibodies. The anti-APP $373 \mathrm{~N}$ anti-APP585N and anti-APP 585C antibodies were generated by immunizing rabbits with the following peptides: Ac-CESLEQEAAN-OH (anti-APP373N), Ac-CTRPGSGLTN-OH (anti-APP 585N) and H2N-IKTEEISEVC-amide (anti-APP 585C), respectively. The antiserum was pooled and the titres against the immunizing peptide were determined by ELISA. The maximal dilution giving a positive response using chromogenic substrate for HRP was $>1: 30,000$. The immunoactivity of the antiserum was further confirmed by western blot and immunohistochemistry.

Electron microscopy. Synaptic density was determined by electron microscopy. After deep anaesthesia, mice were perfused transcardially with $2 \%$ glutaraldehyde and 3\% paraformaldehyde in PBS. Hippocampal slices were postfixed in cold $1 \%$ $\mathrm{OsO}_{4}$ for $1 \mathrm{~h}$. Samples were prepared and examined using standard procedures.
Ultrathin sections $(90 \mathrm{~nm})$ were stained with uranyl acetate and lead acetate, and viewed at $100 \mathrm{kV}$ in a JEOL 200CX electron microscope. Synapses were identified by the presence of synaptic vesicles and postsynaptic densities.

Golgi staining. Mouse brains were fixed in $10 \%$ formalin for $24 \mathrm{~h}$, and then immersed in $3 \%$ potassium bichromate for 3 days in the dark. The solution was changed each day. Then the brains were transferred into $2 \%$ silver nitrate solution and incubated for $24 \mathrm{~h}$ in the dark. Vibratome sections were cut at $60 \mu \mathrm{m}$, air dried for $10 \mathrm{~min}$, dehydrated through 95 and $100 \%$ ethanol, cleared in xylene and coverslipped.

Electrophysiology. Acute hippocampal transversal slices were prepared from 6-month-old WT, $\mathrm{AEP}^{-l-}, 5 \mathrm{XFAD}$ and $5 \mathrm{XFAD} / \mathrm{AEP}^{-/-}$mice as described previously ${ }^{63}$. Briefly, mice hippocampal slices were placed in a recording chamber (RC-22C, Warner Instruments) on the stage of an upright microscope (Olympus CX-31) and perfused at a rate of $3 \mathrm{ml} \mathrm{min}^{-1}$ with a-CSF (containing $1 \mathrm{mM} \mathrm{MgCl} 2$ ) at $23-24^{\circ} \mathrm{C}$. A $0.1 \mathrm{M} \Omega$ tungsten monopolar electrode was used to stimulate the Schaffer collaterals. The field excitatory postsynaptic potentials (fEPSPs) were recorded in CA1 stratum radiatum by a glass microelectrode filled with a-CSF with resistance of 3-4M $\Omega$. The stimulation output (Master-8; AMPI, Jerusalem) was controlled by the trigger function of an EPC9 amplifier (HEKA Elektronik, Lambrecht, Germany). fEPSPs were recorded under current-clamp mode. Data were filtered at $3 \mathrm{kHz}$ and digitized at sampling rates of $20 \mathrm{kHz}$ using Pulse software (HEKA Elektronik). The stimulus intensity $(0.1 \mathrm{~ms}$ duration, $3-4.5 \mathrm{~V})$ was set to evoke $40 \%$ of the maximum fEPSP and the test pulse was applied at a rate of $0.033 \mathrm{~Hz}$. LTP of fEPSPs was induced by three theta-burst stimulation, it is four pulses at $100 \mathrm{~Hz}$, repeated three times with a 200-ms interval).

Mice brain tissue preparation and protein extraction. After completion of the behavioural test, mice were deeply anaesthetized with pentobarbital and transcardially perfused with saline, and the brains were rapidly removed. One hemisphere was fixed in $4 \%$ phosphate-buffered paraformaldehyde, while the other was snap frozen for biochemical analysis. For brain protein extraction, hemispheres were first extracted in RIPA buffer $(25 \mathrm{mM}$ Tris- $\mathrm{HCl}, \mathrm{pH} 7.5,150 \mathrm{mM} \mathrm{NaCl}, 1 \%$ NP- $40,0.5 \% \mathrm{NaDOC}$ and $0.1 \% \mathrm{SDS}$ ), centrifuged at 100,000 r.p.m. for $30 \mathrm{~min}$ and the pellet containing insoluble $\mathrm{A} \beta$ was further extracted in $2 \%$ SDS, $25 \mathrm{mM}$ Tris- $\mathrm{HCl}, \mathrm{pH} 7.5$.

ELISA quantification of A $\boldsymbol{\beta}$. To detect the concentration of $A \beta$ in total brain lysates, the mouse brains were homogenized in $8 \times$ mass of $5 \mathrm{M}$ guanidine $\mathrm{HCl} / 50 \mathrm{mM}$ Tris- $\mathrm{HCl}(\mathrm{pH} 8.0$ ), and incubated at room temperature for $3 \mathrm{~h}$. Then the samples were diluted with cold reaction buffer (PBS with 5\% BSA and 0.03\% Tween-20, supplemented with protease inhibitor cocktail), and centrifuged at $16,000 \mathrm{~g}$ for $20 \mathrm{~min}$ at $4{ }^{\circ} \mathrm{C}$. The $\mathrm{A} \beta$ in the total brain and the $\mathrm{A} \beta$ in the SDS fraction were analysed with human A $\beta 42$ (KHB3441, Invitrogen), A $\beta 40$ (KHB3481, Invitrogen) and total A $\beta$ (SIG-38966, Covance) ELISA kits according to the manufacturer's instructions. The A $\beta$ concentrations were determined by comparison with the standard curve. To assess the effect of $A E P$ on $A \beta$ production, HEK293 cells stably transfected with human APP695 were transfected with small interfering RNA (siRNA) against AEP using lipofection 2000 reagent. AEP 27mer siRNA was purchased from Origene. The siRNA sequences are rCrCrArUrGrGr ArUrCrUrArCrUrGrGrArArUrArCrUrGrGTT, ArGrCrGrUrCrArArCrUrGrGr ArUrGrGrArArGrArUrUrCGG. Non-targeting control siRNA (rCrGrUrUrAr ArUrCrGrCrGrUrArUrArArUrArCrGrCrGrUrArT) was transfected in parallel as control. To detect the A $\beta$ production by different APP fragments, HEK293 cells were transfected with GST-APP full length, GST-APP ${ }_{374-695}$, GST-APP S86-695, GFP-APP, GFP-APP N373A and GFP-APP N585A, respectively. Twenty-four hours post-transfection, cells were fed with fresh media. Media were collected after conditioning for $24 \mathrm{~h}$, and cell debris was removed by centrifugation. Complete protease inhibitor cocktail (Roche) was added and $\mathrm{A} \beta 40$ and $\mathrm{A} \beta 42$ were quantified with human $\mathrm{A} \beta 42$ and $\mathrm{A} \beta 40$ ELISA kits (KHB3441 and KHB3481, Invitrogen). The concentrations of $\mathrm{A} \beta 42$ and $\mathrm{A} \beta 40$ in $\mathrm{AEP}^{+1+}$ and $\mathrm{AEP}^{-1-}$ mouse neuronal medium were analysed using mouse $A \beta 42$ and $A \beta 40$ ELISA kits (KMB3441 and KMB3481, Invitrogen).

ELISA quantification of APP fragments. The ELISA was carried out by using 96-well Nunc-Immuno MaxSorp platesfor TMB (3,3',5,5'-tetramethylbenzidine from Sigma Catalogue \# T5525). These plates were coated with $100 \mu$ lantibody that specifically recognize AEP-derived APP fragment ${ }_{586-695}$ (1:200). The plates were incubated overnight at $4{ }^{\circ} \mathrm{C}$ and then washed once with $250 \mu$ of PBS/Tween-20 (PBST; $0.5 \%, \mathrm{v} / \mathrm{v}$ ) for $1 \mathrm{~min}$ and removed; the coated plates were blocked by adding $200 \mu \mathrm{l}$ per well of $2 \%$ BSA in PBST for $2 \mathrm{~h}$ at room temperature. After blocking, $100 \mu \mathrm{l}$ per well of samples diluted in $2 \% \mathrm{BSA} / \mathrm{PBST}\left(+2 \mathrm{mM} \mathrm{Na}_{3} \mathrm{VO}_{4}\right)$ were added to each well and the plate was incubated overnight at $4{ }^{\circ} \mathrm{C}$ and washed four times with $250 \mathrm{ml}$ of PBST next day. After washing, $100 \mu \mathrm{l}$ per well of the CT15 that was diluted with ratio of 1:1,000 in $2 \%$ BSA/PBST was added and incubated overnight at $4{ }^{\circ} \mathrm{C}$ and then washed. After rinsing with PBST for three or four times, $100 \mu \mathrm{l}$ per 
well of anti-mouse HRP-conjugated secondary antibody (Fisher) 1:5,000 diluted in $2 \%$ BSA/PBST was added and incubated for $2 \mathrm{~h}$ at room temperature and then rinsed with $250 \mathrm{ml}$ PBST for three times. After the final wash, $100 \mathrm{ml}$ of the substrate solution (TMB solution: to dissolve TMB $1 \mathrm{mg}$ tablet in $1 \mathrm{ml}$ dimethylsulfoxide, and freshly dilute to $9 \mathrm{ml} \mathrm{pH} 5.0$ citrate buffer (to $50 \mathrm{ml}$ de-ionized water, add $20.5 \mathrm{ml} 0.1 \mathrm{M}$ citric acid plus $29.5 \mathrm{ml} 0.1 \mathrm{M}$ sodium citrate, mix well) and add $100 \mathrm{ml} 3 \% \mathrm{H}_{2} \mathrm{O}_{2}$ ) was added to each well and incubated at $37^{\circ} \mathrm{C}$ for $10-30 \mathrm{~min}$. The reaction was stopped by adding $50 \mu \mathrm{l}$ per well of $3 \mathrm{~N} \mathrm{HCl}$ and the values of each well were recorded using microplate reader at $450 \mathrm{~nm}$ or luminescent, and subtract the readings at $650 \mathrm{~nm}$ from the readings at $450 \mathrm{~nm}$. This subtraction will correct the optical imperfections in the plate.

Morris water maze. Six-month-old WT, $\mathrm{AEP}^{-1-}, 5 \mathrm{XFAD}, 5 \mathrm{XFAD} / \mathrm{AEP}^{-1-}$ mice and 15-month-old APP/PS1 and APP/PS1/AEP ${ }^{-1-}$ mice were trained in a round, water-filled tub (52 inch diameter) in an environment rich with extra maze cues. An invisible escape platform was located in a fixed spatial location $1 \mathrm{~cm}$ below the water surface independent of a subject's start position on a particular trial. In this manner, subjects needed to utilize extra maze cues to determine the platform's location. At the beginning of each trial, the mouse was placed in the water maze with their paws touching the wall from 1 of 4 different starting positions (N, S, E and $\mathrm{W}$ ). Each subject was given four trials per day for 5 consecutive days with a 15 -min inter-trial interval. The maximum trial length was $60 \mathrm{~s}$ and if subjects did not reach the platform in the allotted time, they were manually guided to it. On reaching the invisible escape platform, subjects were left on it for an additional $5 \mathrm{~s}$ to allow for survey of the spatial cues in the environment to guide future navigation to the platform. After each trial, subjects were dried and kept in a dry plastic holding cage filled with paper towels to allow the subjects to dry off. The temperature of the water was monitored every hour so that mice were tested in water that was between 22 and $25^{\circ} \mathrm{C}$. Following the 5 days of task acquisition, a probe trial was presented during which time the platform was removed and the percentage of time spent in the quadrant, which previously contained the escape platform during task acquisition was measured over $60 \mathrm{~s}$. All trials were analysed for latency and swim speed by means of MzeScan (Clever Sys, Inc.).

Immunofluorescence. Cultured neurons were fixed in $4 \%$ formaldehyde for 10 min, washed with PBS, blocked in $1 \%$ BSA and $0.3 \%$ Triton X-100 for $30 \mathrm{~min}$ followed by overnight incubation with primary antibodies at $4{ }^{\circ} \mathrm{C}$. The slides were washed three times in PBS and incubated with Texas Red-conjugated anti-mouse IgG and fluorescein isothiocyanate-conjugated anti-rabbit IgG for $1 \mathrm{~h}$ at room temperature. The slides were washed three times in PBS, then the sections were covered with a glass cover using mounting solution and examined using fluorescence microscopy or confocal microscopy (Olympus).

Primary neuron culture. Primary neurons were dissected from E18 embryos and cultured as described previously ${ }^{63}$. To measure the effect of APP fragments on neurons, primary cortical neurons cultured 12 days in vitro (DIV 12) were exposed to different concentrations of APP fragments for $24 \mathrm{~h}$, the neurons were then fixed in $4 \%$ formaldehyde, permeabilized and immunostained with anti-MAP2 antibody $(1: 1,000)$. Pictures of the neurons were taken by fluorescence microscopy. Neuronal apoptosis was detected with the In Situ Cell Death Detection Kit. The apoptotic index was expressed as the percentage of TUNEL-positive neurons out of the total number of MAP2-positive neurons. To detect the effect of $\mathrm{APP}_{1-373}$ on HEK293 cells and PC12 cells (from ATCC), the cells were incubated with APP ${ }_{1-373}$ at $10 \mu \mathrm{g} \mathrm{ml}^{-1}$ for $24 \mathrm{~h}$. The cells were fixed and stained with In situ Cell Death Detection Kit and 4,6-diamidino-2-phenylindole. The percentage of TUNEL-positive nucleus out of the total nucleus was calculated.

AAV vector packaging. pAAV vectors carrying human APP SLA were gifts from Dr Kuegler from Max Planck Institute of Psychiatry, Germany ${ }^{40}$. The vectors use the human synapsin I promoter to drive neuron-specific gene expression. All of the mutations were introduced using site-directed mutagenesis kit (Agilent Technologies). The AAV particles were prepared by Viral Vector Core at Emoy University.

Stereotaxic injection of the virus. Three-month-old WT C57BL/6J mice were anaesthetized with phenobarbital $\left(75 \mathrm{mg} \mathrm{kg}^{-1}\right)$. Bilateral intracerebral injection of AAV-APP SLA and AAV-APP SLA N373AN585A was performed stereotactically at coordinates posterior $1.94 \mathrm{~mm}$, lateral $1.4 \mathrm{~mm}$ and ventral $2.2 \mathrm{~mm}$ relative to bregma. A volume of $2 \mu \mathrm{l}$ of viral suspension containing $2 \times 10^{11}$ vector genome was injected in to each point using $10-\mu$ l glass syringes with a fixed needle at a rate of $0.5 \mu \mathrm{min}^{-1}$. The needle was remained in place for $5 \mathrm{~min}$ before it was removed slowly (throughout $2 \mathrm{~min}$ ). The mice were placed on heating pad until it began to recover from the surgery.

Statistical analysis. All the quantitative data were presented as mean \pm s.e.m. Statistical analysis was performed using either Student's $t$-test (two-group comparison) or one-way analysis of variance (more than two groups) followed by post hoc comparison, and differences with $P$ values $<0.05$ were considered significant.

\section{References}

1. Selkoe, D. J. Amyloid beta-protein and the genetics of Alzheimer's disease. J. Biol. Chem. 271, 18295-18298 (1996).

2. Haass, C. Take five-BACE and the gamma-secretase quartet conduct Alzheimer's amyloid beta-peptide generation. EMBO J. 23, 483-488 (2004)

3. Kang, J. et al. The precursor of Alzheimer's disease amyloid A4 protein resembles a cell-surface receptor. Nature 325, 733-736 (1987).

4. Dyrks, T. et al. Identification, transmembrane orientation and biogenesis of the amyloid A4 precursor of Alzheimer's disease. EMBO J. 7, 949-957 (1988).

5. Haass, C., Kaether, C., Thinakaran, G. \& Sisodia, S. Trafficking and proteolytic processing of APP. Cold Spring Harb. Perspect. Med. 2, a006270 (2012).

6. Vassar, R. BACE1: the beta-secretase enzyme in Alzheimer's disease. J. Mol. Neurosci. 23, 105-114 (2004).

7. Hong, L. et al. Structure of the protease domain of memapsin 2 (beta-secretase) complexed with inhibitor. Science 290, 150-153 (2000).

8. Vassar, R. et al. Beta-secretase cleavage of Alzheimer's amyloid precursor protein by the transmembrane aspartic protease BACE. Science 286, 735-741 (1999).

9. Kaether, C., Haass, C. \& Steiner, H. Assembly, trafficking and function of $\gamma$-secretase. Neurodegener. Dis. 3, 275-283 (2006).

10. Campbell, W. A., Reed, M. L., Strahle, J., Wolfe, M. S. \& Xia, W. Presenilin endoproteolysis mediated by an aspartyl protease activity pharmacologically distinct from gamma-secretase. J. Neurochem. 85, 1563-1574 (2003).

11. Esch, F. S. et al. Cleavage of amyloid beta peptide during constitutive processing of its precursor. Science 248, 1122-1124 (1990).

12. Vingtdeux, V. \& Marambaud, P. Identification and biology of alpha-secretase. J. Neurochem. 120(Suppl 1): 34-45 (2012).

13. Kuhn, P. H. et al. ADAM10 is the physiologically relevant, constitutive alpha-secretase of the amyloid precursor protein in primary neurons. $E M B O \mathrm{~J}$. 29, 3020-3032 (2010).

14. Lammich, S. et al. Constitutive and regulated alpha-secretase cleavage of Alzheimer's amyloid precursor protein by a disintegrin metalloprotease. Proc. Natl Acad. Sci. USA 96, 3922-3927 (1999).

15. Chen, J. M. et al. Cloning, isolation, and characterization of mammalian legumain, an asparaginyl endopeptidase. J. Biol. Chem. 272, 8090-8098 (1997).

16. Chen, J. M., Dando, P. M., Stevens, R. A., Fortunato, M. \& Barrett, A. J. Cloning and expression of mouse legumain, a lysosomal endopeptidase. Biochem. J. 335(Pt 1): 111-117 (1998).

17. Li, D. N., Matthews, S. P., Antoniou, A. N., Mazzeo, D. \& Watts, C. Multistep autoactivation of asparaginyl endopeptidase in vitro and in vivo. J. Biol. Chem. 278, 38980-38990 (2003)

18. Shirahama-Noda, K. et al. Biosynthetic processing of cathepsins and lysosomal degradation are abolished in asparaginyl endopeptidase-deficient mice. J. Biol Chem. 278, 33194-33199 (2003).

19. Liu, Z. et al. Neuroprotective actions of PIKE-L by inhibition of SET proteolytic degradation by asparagine endopeptidase. Mol. Cell 29, 665-678 (2008).

20. Madeira, A., Pommet, J. M., Prochiantz, A. \& Allinquant, B. SET protein (TAFlbeta, I2PP2A) is involved in neuronal apoptosis induced by an amyloid precursor protein cytoplasmic subdomain. FASEB J. 19, 1905-1907 (2005).

21. Basurto-Islas, G., Grundke-Iqbal, I., Tung, Y. C., Liu, F. \& Iqbal, K. Activation of asparaginyl endopeptidase leads to tau hyperphosphorylation in Alzheimer disease. J. Biol. Chem. 288, 17495-17507 (2013).

22. Herskowitz, J. H. et al. Asparaginyl endopeptidase cleaves TDP-43 in brain Proteomics 12, 2455-2463 (2012).

23. Zhang, Z. et al. Cleavage of tau by asparagine endopeptidase mediates the neurofibrillary pathology in Alzheimer's disease. Nat. Med. 20, 1254-1262 (2014).

24. Levy, E. et al. Codeposition of cystatin C with amyloid-beta protein in the brain of Alzheimer disease patients. J. Neuropathol. Exp. Neurol. 60, 94-104 (2001).

25. Kaur, G. \& Levy, E. Cystatin C in Alzheimer's disease. Front. Mol. Neurosci. 5, 79 (2012).

26. Smith, R. et al. Intra- and extracellular regulation of activity and processing of legumain by cystatin E/M. Biochimie 94, 2590-92012 (2012).

27. Zhao, L. et al. Structural analysis of asparaginyl endopeptidase reveals the activation mechanism and a reversible intermediate maturation stage. Cell Res. 24, 344-358 (2014).

28. Loak, K. et al. Novel cell-permeable acyloxymethylketone inhibitors of asparaginyl endopeptidase. Biol. Chem. 384, 1239-1246 (2003).

29. Zhang, Y. et al. An RNA-sequencing transcriptome and splicing database of glia, neurons, and vascular cells of the cerebral cortex. J. Neurosci. 34, 11929-11947 (2014).

30. Weidemann, A. et al. Proteolytic processing of the Alzheimer's disease amyloid precursor protein within its cytoplasmic domain by caspase-like proteases. J. Biol. Chem. 274, 5823-5829 (1999). 
31. Mueller-Steiner, S. et al. Antiamyloidogenic and neuroprotective functions of cathepsin B: implications for Alzheimer's disease. Neuron 51, $703-714$ (2006).

32. Tesco, G. et al. Depletion of GGA3 stabilizes BACE and enhances beta-secretase activity. Neuron 54, 721-737 (2007).

33. Tu, S., Okamoto, S., Lipton, S. A. \& Xu, H. Oligomeric A $\beta$-induced synaptic dysfunction in Alzheimer's disease. Mol. Neurodegener. 9, 48 (2014).

34. Smith, R. et al. Intracellular localization of amyloid- $\beta$ peptide in SH-SY5Y neuroblastoma cells. J. Alzheimers Dis. 37, 713-733 (2012).

35. Nikolaev, A., McLaughlin, T., O’Leary, D. D. \& Tessier-Lavigne, M. APP binds DR6 to trigger axon pruning and neuron death via distinct caspases. Nature 457, 981-989 (2009).

36. Haass, C. \& Selkoe, D. J. Soluble protein oligomers in neurodegeneration: lessons from the Alzheimer's amyloid beta-peptide. Nat. Rev. Mol. Cell Biol. 8, 101-112 (2007).

37. Shankar, G. M. \& Walsh, D. M. Alzheimer's disease: synaptic dysfunction and Abeta. Mol. Neurodegener 4, 48 (2009).

38. Hongpaisan, J., Sun, M. K. \& Alkon, D. L. PKC epsilon activation prevents synaptic loss, Abeta elevation, and cognitive deficits in Alzheimer's disease transgenic mice. J. Neurosci. 31, 630-643 (2011).

39. Kimura, R. \& Ohno, M. Impairments in remote memory stabilization precede hippocampal synaptic and cognitive failures in 5XFAD Alzheimer mouse model. Neurobiol. Dis. 33, 229-235 (2009).

40. Jaworski, T. et al. AAV-tau mediates pyramidal neurodegeneration by cell-cycle re-entry without neurofibrillary tangle formation in wild-type mice. PLoS ONE 4, e7280 (2009).

41. Hardy, J. \& Selkoe, D. J. The amyloid hypothesis of Alzheimer's disease: progress and problems on the road to therapeutics. Science 297, 353-356 (2002).

42. Mawuenyega, K. G. et al. Decreased clearance of CNS $\beta$-amyloid in Alzheimer's disease. Science 330, 1774-1774 (2010).

43. Nilsberth, C. et al. The 'Arctic' APP mutation (E693G) causes Alzheimer's disease by enhanced A $\beta$ protofibril formation. Nat. Neurosci. 4, 887-893 (2001).

44. Yang, L.-B. et al. Elevated $\beta$-secretase expression and enzymatic activity detected in sporadic Alzheimer disease. Nat. Med. 9, 3-4 (2003).

45. Li, R. et al. Amyloid $\beta$ peptide load is correlated with increased $\beta$-secretase activity in sporadic Alzheimer's disease patients. Proc. Natl Acad. Sci. USA 101, 3632-3637 (2004).

46. Silverberg, G. et al. Continuous CSF drainage in AD results of a double-blind, randomized, placebo-controlled study. Neurology 71, 202-209 (2008).

47. Kurz, A. \& Perneczky, R. Amyloid clearance as a treatment target against Alzheimer's disease. J. Alzheimers Dis. 24, 61-73 (2010).

48. Weidemann, A. et al. Identification, biogenesis, and localization of precursors of Alzheimer's disease A4 amyloid protein. Cell 57, 115-126 (1989).

49. Lu, D. C., Soriano, S., Bredesen, D. E. \& Koo, E. H. Caspase cleavage of the amyloid precursor protein modulates amyloid beta-protein toxicity. J. Neurochem. 87, 733-741 (2003).

50. Harris, J. A. et al. Many neuronal and behavioral impairments in transgenic mouse models of Alzheimer's disease are independent of caspase cleavage of the amyloid precursor protein. J. Neurosci. 30, 372-381 (2010).

51. Golde, T. E., Estus, S., Younkin, L. H., Selkoe, D. J. \& Younkin, S. G. Processing of the amyloid protein precursor to potentially amyloidogenic derivatives. Science 255, 728-730 (1992).

52. Haass, C., Koo, E. H., Mellon, A., Hung, A. Y. \& Selkoe, D. J. Targeting of cell-surface beta-amyloid precursor protein to lysosomes: alternative processing into amyloid-bearing fragments. Nature 357, 500-503 (1992).

53. Hook, V. Y., Kindy, M. \& Hook, G. Inhibitors of cathepsin B improve memory and reduce beta-amyloid in transgenic Alzheimer disease mice expressing the wild-type, but not the Swedish mutant, beta-secretase site of the amyloid precursor protein. J. Biol. Chem. 283, 7745-7753 (2008).

54. Hook, V. Y., Kindy, M., Reinheckel, T., Peters, C. \& Hook, G. Genetic cathepsin $\mathrm{B}$ deficiency reduces beta-amyloid in transgenic mice expressing human wild-type amyloid precursor protein. Biochem. Biophys. Res. Commun. 386, 284-288 (2009).

55. Cataldo, A. M., Paskevich, P. A., Kominami, E. \& Nixon, R. A. Lysosomal hydrolases of different classes are abnormally distributed in brains of patients with Alzheimer disease. Proc. Natl Acad. Sci. USA 88, 10998-11002 (1991).

56. Clerin, V. et al. Expression of the cysteine protease legumain in vascular lesions and functional implications in atherogenesis. Atherosclerosis 201, 53-66 (2008).

57. Holland, M. et al. RAC2, AEP, and ICAM1 expression are associated with CNS disease in a mouse model of pre-B childhood acute lymphoblastic leukemia. Blood 118, 638-649 (2011).

58. Chan, C. B. et al. Mice lacking asparaginyl endopeptidase develop disorders res.e.m.bling hemophagocytic syndrome. Proc. Natl Acad. Sci. USA 106, 468-473 (2009).

59. Sisodia, S., Koo, E., Hoffman, P., Perry, G. \& Price, D. Identification and transport of full-length amyloid precursor proteins in rat peripheral nervous system. J. Neurosci. 13, 3136-3142 (1993).

60. Santosa, C. et al. Decreased expression of GGA3 protein in Alzheimer's disease frontal cortex and increased co-distribution of BACE with the amyloid precursor protein. Neurobiol. Dis. 43, 176-183 (2011).

61. Elias, J. E. \& Gygi, S. P. Target-decoy search strategy for increased confidence in large-scale protein identifications by mass spectrometry. Nat. Methods $\mathbf{4}$, 207-214 (2007).

62. Xu, P., Duong, D. M. \& Peng, J. Systematical optimization of reverse-phase chromatography for shotgun proteomics. J. Proteome Res. 8, 3944-3950 (2009).

63. Zhang, Z. et al. 7,8-dihydroxyflavone prevents synaptic loss and memory deficits in a mouse model of Alzheimer's disease. Neuropsychopharmacology 39, 638-650 (2014).

\section{Acknowledgements}

This work was supported by grants RO1 (NS045627 and 060680) from NIH to K.Y., the NIH/NIAP50 AG025688 ADRC Center Grant to A.I.L., grants from National Natural Science Foundation of China (No. 81100958, 81571249) to Z.Z., National Key Basic Research Program of China Grant (2010CB945202) to Y.E.S. and National Science Foundation of China Grant (81330030) to L.C. and Y.E.S. We are thankful to the kind gift of anti-APP C-terminal antibody (CT15) and HEK293 cells stably transfected with human APP695 from Dr Edward Koo, University of California; ADAM10/17 knockout mouse embryonic fibroblasts (MEFs) from Dr Paul Saftig, Christian-AlbrechtsUniversity Kiel, Germany; BACE1 knockout MEFs from Dr Philip Wong, Johns Hopkins University; and PS1/PS2 knockout MEFs from Dr Bart De Strooper, Belgium VIB Center for the Biology of Disease, Belgium.

\section{Author contributions}

K.Y. conceived the project, designed the experiments, and wrote the manuscript; Z.Z. performed most of the experiments; M.S. and S.P.Y. performed the electrophysiological experiments; X.L. and S.S.K. prepared primary neurons and assessed with animal experiments; D.M.D. and N.T.S. performed the mass spectrometry analysis; X.C., L.C., Y.E.S., J.J. and A.I.L. assisted with data analysis and interpretation and critically read the manuscript.

\section{Additional information}

Supplementary Information accompanies this paper at http://www.nature.com/ naturecommunications

Competing financial interests: The authors declare no competing financial interests.

Reprints and permission information is available online at http://npg.nature.com/ reprintsandpermissions/

How to cite this article: Zhang, Z. et al. Delta-secretase cleaves amyloid precursor protein and regulates the pathogenesis in Alzheimer's disease. Nat. Commun. 6:8762 doi: $10.1038 /$ ncomms9762 (2015).

This work is licensed under a Creative Commons Attribution 4.0 International License. The images or other third party material in this article are included in the article's Creative Commons license, unless indicated otherwise in the credit line; if the material is not included under the Creative Commons license, users will need to obtain permission from the license holder to reproduce the material. To view a copy of this license, visit http://creativecommons.org/licenses/by/4.0/ 